\title{
Analysis of changes in air pollution quality and impact of COVID-19 on environmental health in Iran: application of interpolation models and spatial autocorrelation
}

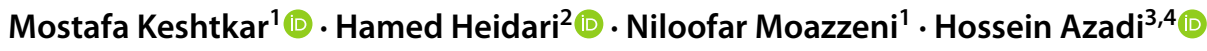

Received: 27 July 2021 / Accepted: 1 December 2021 / Published online: 26 January 2022

(c) The Author(s), under exclusive licence to Springer-Verlag GmbH Germany, part of Springer Nature 2021

\begin{abstract}
In the global COVID-19 epidemic, humans are faced with a new challenge. The concept of quarantine as a preventive measure has changed human activities in all aspects of life. This challenge has led to changes in the environment as well. The air quality index is one of the immediate concrete parameters. In this study, the actual potential of quarantine effects on the air quality index and related variables in Tehran, the capital of Iran, is assessed, where, first, the data on the pollutant reference concentration for all measuring stations in Tehran, from February 19 to April 19, from 2017 to 2020, are monitored and evaluated. This study investigated the hourly concentrations of six particulate matters (PM), including PM2.5, PM10, and air contaminants such as nitrogen dioxide $\left(\mathrm{NO}_{2}\right)$, sulfur dioxide (SO2), ozone (O3), and carbon monoxide (CO). Changes in pollution rate during the study period can be due to reduced urban traffic, small industrial activities, and dust mites of urban and industrial origins. Although pollution has declined in most regions during the COVID-19 quarantine period, the PM2.5 rate has not decreased significantly, which might be of natural origins such as dust. Next, the air quality index for the stations is calculated, and then, the interpolation is made by evaluating the root mean square (RMS) of different models. The local and global Moran index indicates that the changes and the air quality index in the study area are clustered and have a high spatial autocorrelation. The results indicate that although the bad air quality is reduced due to quarantine, major changes are needed in urban management to provide favorable conditions. Contaminants can play a role in transmitting COVID-19 as a carrier of the virus. It is suggested that due to the rise in COVID-19 and temperature in Iran, in future studies, the effect of increased temperature on COVID-19 can be assessed.
\end{abstract}

Keywords Coronavirus $\cdot$ Air quality index $\cdot$ Pollution impact $\cdot$ Local and global Moran index $\cdot$ GIS

Responsible Editor: Marcus Schulz

Summary: "The results indicate that the air quality index has decreased compared to the 2017-2019 average and the pollutant parameters have changed and are close to local and global clean ratings."

Hamed Heidari

hamed.heidari@alumni.ut.ac.ir

1 Environmental Sciences Research Institute, Department of Environmental Planning, University of Shahid Beheshti, Tehran, Iran

2 School of Environment, College of Engineering, Department of Environmental Planning, Management \& Education, University of Tehran, Tehran, Iran

3 Research Group Climate Change and Security, Institute of Geography, University of Hamburg, Hamburg, Germany

4 Faculty of Environmental Sciences, Czech University of Life Sciences Prague, Prague, Czech Republic

\section{Introduction}

In late December 2019, a new strain of an infectious disease was discovered in Wuhan, China, and was named COVID19 (Chen et al. 2020a, b, c; Zhang et al. 2021; Afify et al. 2021). This virus, which is a human-to-human transmitted virus (Wang et al. 2020; Wang and Su 2020), causes an acute respiratory infection that can progress to pneumonia if the symptoms are not treated (Jiang et al. 2020a, b; Coccia 2021). The findings indicate that old age is one of its risk factors (Luo et al. 2020; Wang and Zhao 2021) with an approximate $2-3 \%$ fatality rate (total infected people who died) (Rodriguez-Morales et al. 2020; Bonilla-Aldana et al. 2020). On February 19, 2020, the Iranian Ministry of Health officially reported that two patients with pneumonia were associated with COVID-19 in the city of Qom. Gilan, Arak, and Tehran were the other provinces where this virus 
spread widely. Thereafter, the count of infected populations increased rapidly, and within 1 month, the outbreak became a national crisis, with infected individuals diagnosed all over the country (Iran Health Organization 2020). To control this infection, the National Corona Committee was deployed with subcommittees in each province. To prevent the spread of the disease, this committee has enacted measures to ban traffic at different times of the day and close or reduce the operation time of high-risk industries, factories, etc. These measures were lifted from 13 to 20 April. As of 4 May, the confirmed cases are 97,424, and the deaths are 6203 (World Health Organization 2020).

Despite all the negative impacts assigned to COVID-19, one of the positive aspects of the quarantine situation is the reduced transportation which led to cleaner air. Many destructive and quality-degrading environmental problems caused by humans have plagued the Earth since the beginning of the twentieth century. Today, air pollutants are one of the most common environmental and health problems in developed and developing countries. This is caused by everincreasing fossil fuel consumption (Shen et al. 2021; Wang and Zhang 2021). This problem has its cultural, economic, social, and political dimensions, which can be controlled through planning, inter-sectoral cooperation, and comprehensive and efficient management at the national level (Wang and Su 2020). The effect of air quality on public health has been well documented and studied with different scientific methods to protect human health and prevent environmental degradation. Human manipulative intervention of any kind in the environment has endangered human health and damaged ecosystems (Bai et al. 2020). Human wellbeing and the environment are threatened by air pollution (Zhu et al. 2020). Scientific findings indicate that, unless air pollution is controlled in the first half of this century, one person would die due to air pollution every five seconds (Gauderman et al. 2015). Studies have found that air pollution is a respiratory infection risk factor, directly involved in the body immunity system (Zhu et al. 2020; He et al. 2020; Muhammad et al. 2020), and some suggested that the microorganisms inhaled from pollutants make pathogens more invasive to humans and affect body immunity (Becker and Soukup 1999; Cai et al. 2007; Xu et al. 2016; Horne et al. 2018; Xie et al. 2019).

When measuring air quality, the most important contaminants that are monitored are particulate matters $(\mathrm{PM})$, as well as $\mathrm{NO}_{2}, \mathrm{CO}, \mathrm{O}_{3}$, and $\mathrm{SO}_{2}$ gases. $\mathrm{PM}$ in the formation of fine particles $10 \mu \mathrm{m}$ or smaller (PM10) can enter the respiratory system through breathing and can cause severe respiratory diseases, among others (Jung et al. 2019). According to some researchers (Xu et al. 2020), PM10 is thought to be caused by five distinct factors: secondary inorganic aerosols, fire, crustal mud, automotive waste, and biomass combustion. Resuspension of dust has also been identified as a cause of particulate matters (Aquilina et al. 2021). Despite the fact that the $\mathrm{O}_{3}$ stratosphere protects the Earth's surface from ultraviolet radiation, certain $\mathrm{O}_{3}$ concentrations on the Earth's surface are toxic to the respiratory and cardiovascular systems owing to their strong oxidative reaction (Sicard et al. 2020). Air pollutants such as NO2, SO2, and CO are toxic to humans, and short- and long-term exposure is associated with a lung infection (Pandey et al. 2021). The spatial autocorrelation model has been identified by several researchers as a beneficial means to investigate the characteristics of spatial improvements in air quality. The use of a spatial autocorrelation model in air quality analysis, according to Liu et al. (2020), could explicitly obtain the aggregation field, and the distribution characteristics show the trend of spatial aggregation and the Clean Air Act (CAA) (limitation on certain air pollutants). Getis and Ord (2010) made a distinction between global and local spatial solidarity. Local solidarity can be applied to obtain the local solidarity field covered in the absence of general autocorrelation. The resemblance of measurements at opposite spatial positions is compared using global autocorrelation statistics. Local spatial autocorrelation figures show that the findings of one spatial location are related to the prospects of another region. Lin and Zhu (2018) used global and local Moran's index to measure the spatial autocorrelation of air quality index (AQI) values and discovered that AQI values had significant spatial dependency and heterogeneity. To assess the spatial association between air quality index and weather conditions in various wards in Jaipur, Dadhich et al. (2018) used Moran's I and LISA for spatial analysis. Moran's I findings revealed a clear positive relationship between AQI and relative humidity, temperature, and wind speed. Identifying the influential features of COVID-19 would contribute to making decisions. An attempt is made in this study to describe how a virus can be as effective as a program and more effective than strategies in ecosystem health. By carefully examining Tehran air quality as an environment-friendly parameter, the impact of COVID-19 on environmental health between 2015 and 2020 was evaluated.

\section{Materials and methods}

This survey was conducted in Tehran, Iran's capital and the country's most populous metropolis. At $1300 \mathrm{~m}$ above sea level, the city has a total area of $730 \mathrm{~km}^{2}$ with a population density of almost 11,800 inhabitants per $\mathrm{km}^{2}$. The seasonal average temperatures of Tehran are in spring $28.6^{\circ} \mathrm{C}$; summer $34.76{ }^{\circ} \mathrm{C}$; autumn $16.86{ }^{\circ} \mathrm{C}$; and winter $12.2^{\circ} \mathrm{C}$ (IMO 2019). The city is divided into four main residential, commercial, industrial, and green space land use categories, and 22 regions are under the supervision of the municipal regions. According to the census department of Iran, in 


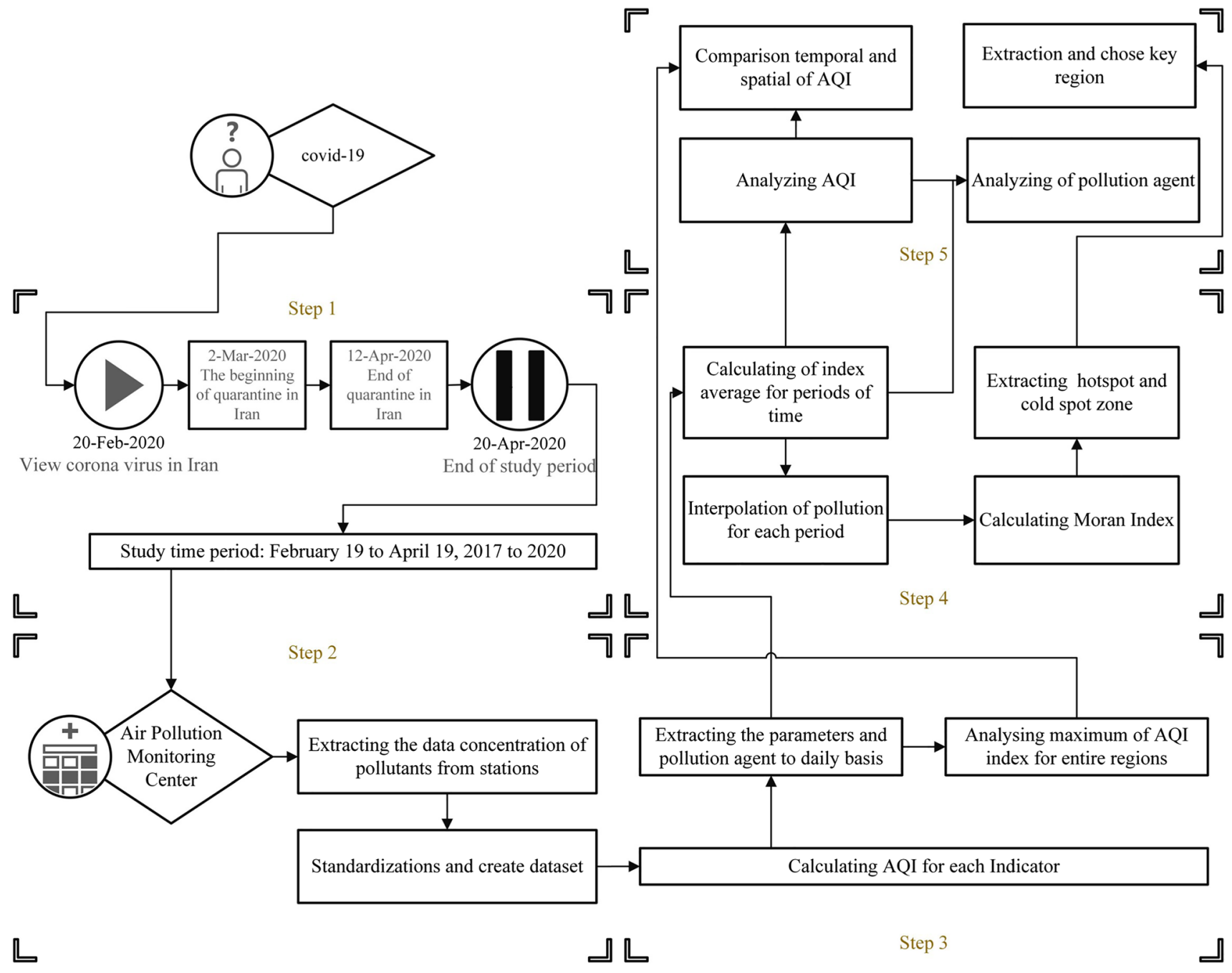

Fig. 1 Research framework. Source: Study’s findings

2015, Tehran's population was 8,737,510 (Mihankhah et al. 2020). The official statistics on the number of the people infected with COVID-19 in Tehran are not available due to the government's confidentiality. However, according to the Iranian Ministry of Health, Tehran has the highest number of confirmed cases and deaths due to COVID-19 (Iran Health Organization 2020).

Figure 1 shows the conceptual framework applied in our methodology. The framework represents the completion of a thorough investigation, as well as the use of accurate information and appropriate indicators in the region. This research is divided into two phases; (i) data collection and calculation of the AQI and (ii) geostatistics and spatial analysis, which are to analyze the measurable effects of quarantine on air quality.

\section{Phase i: data gathering and air quality index (AQI)}

\section{Data collection and time analysis}

At first, statistical available sources were gathered from the pollutant concentrations at pollution measuring stations, from which a dataset was created, and the same target time for the research was chosen. In this regard, Table 1 summarizes the information and features of each station, while Fig. 2 depicts the case study and location of each station. The AQI of different pollutants from February 29, 2015, to April 20, 2020, was analyzed. To clarify the selected dates, April 2020 was the only time that the quarantine was fully implemented. Densities of six pollutants per hour, including PM2.5, PM10, carbon monoxide (CO), nitrogen dioxide $\left(\mathrm{NO}_{2}\right)$, sulfur dioxide $\left(\mathrm{SO}_{2}\right)$, ozone $\left(\mathrm{O}_{3}\right)$, and sulfur dioxide $\left(\mathrm{SO}_{2}\right)$, were obtained from the Air Quality Monitoring 
38508

Environmental Science and Pollution Research (2022) 29:38505-38526

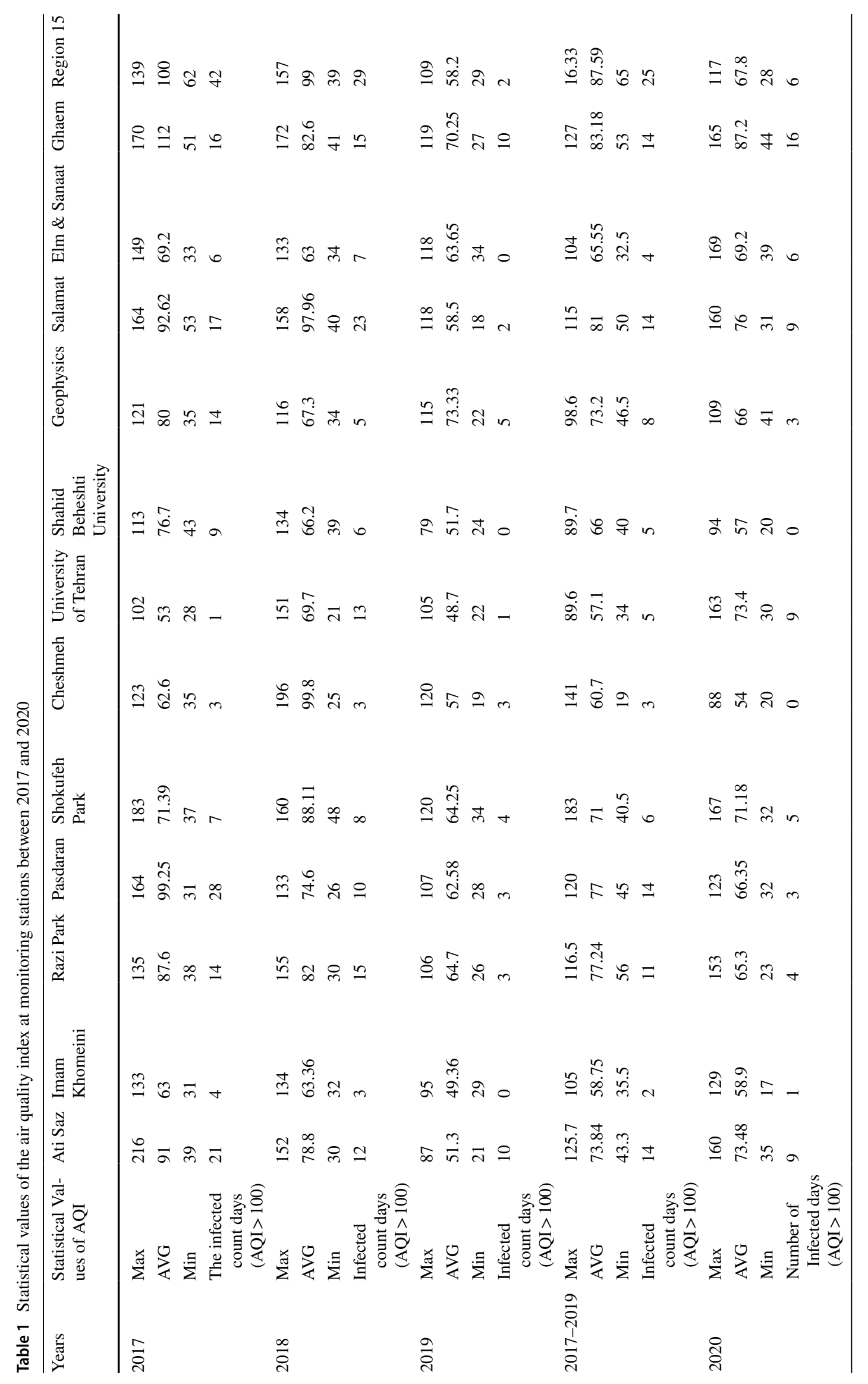

Springer 


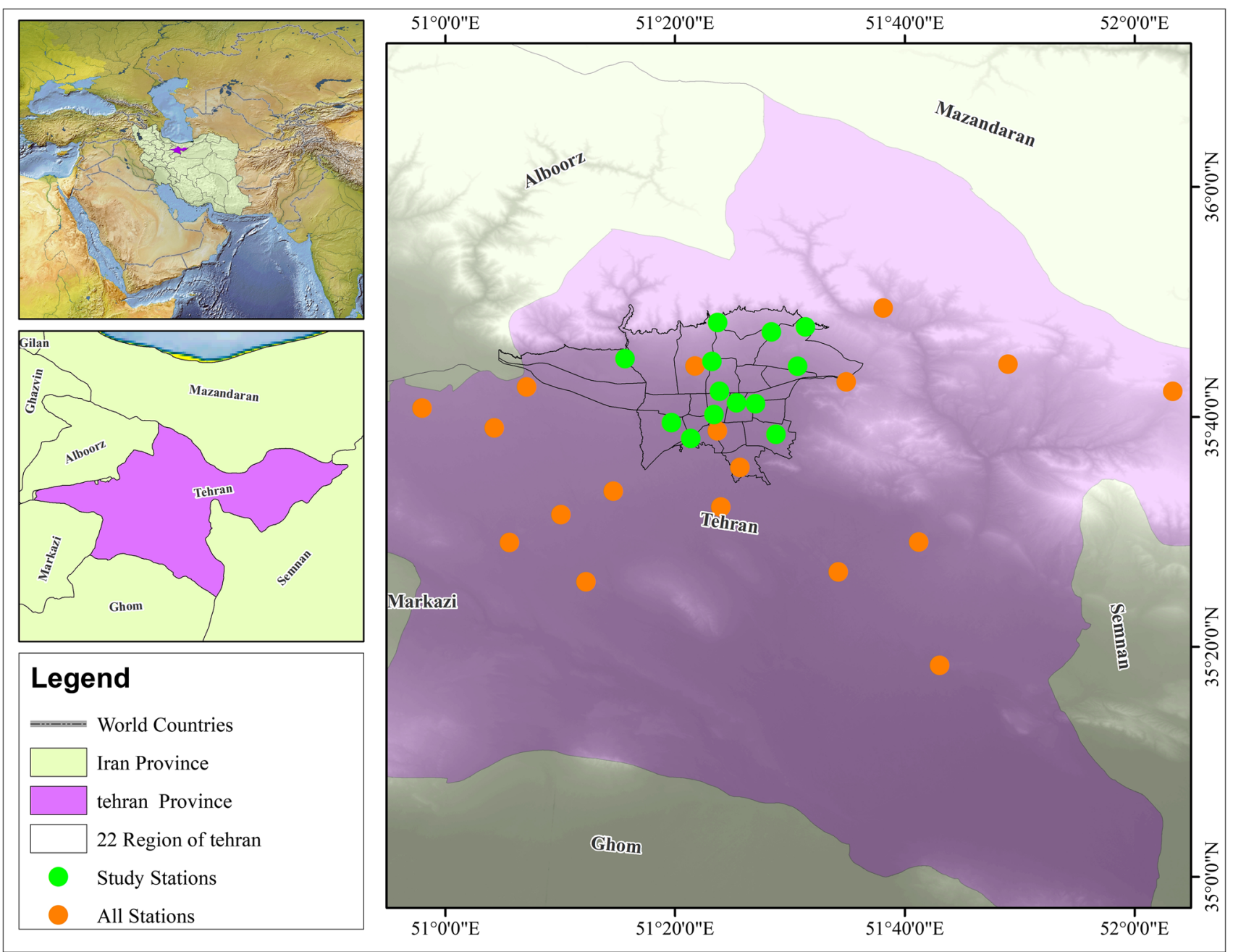

Fig. 2 Stations of air quality which are used in this study

System (AQMS), as well as the online portal for air quality data dissemination (Link).

\section{Air quality index (AQI) calculations}

Air quality affects human life, specifically the respiration system. Just as the weather changes on a daily or hourly basis, the air quality changes too. The AQI as a regular index is a widely used metric of air quality information to educate the general public about the air quality status and its related health risks (Zheng et al. 2014; Jiang and Bai 2018). Monitoring air quality in large cities converts air quality data into the AQI and provides the required information to the public on a daily basis. This index is a key tool applied in knowing air quality and how air pollution affects citizens' health, which provides methods for protection against air pollution.

The AQI is obtained for the main five pollutants, including particulate matters, nitrogen dioxide, ground surface ozone, carbon monoxide, and sulfur dioxide air pollutants (CPCB
2014). Given that the pollutant concentrations are monitored on an hourly basis, the AQI evaluation consists of two stages: (1) recording air pollutants, maximum hourly values for $\mathrm{NO}_{2}$ and $\mathrm{O}_{3}$ and maximum $8 \mathrm{~h}$ for $\mathrm{CO}$, and (2) extracting maximum $\mathrm{O}_{3}$ in $24 \mathrm{~h}$ for PM10, PM2.5, and $\mathrm{SO}_{2}$ according to the standard. The AQI is used to calculate the average change in air quality (Zheng et al. 2014). Equation (1) is used to measure the AQI sub-index for each pollutant I (Song et al. 2020).

$A Q I_{\mathrm{ap}}=\frac{A Q I_{\mathrm{uc}}-A Q I_{\mathrm{lc}}}{B P_{\mathrm{uc}}-B P_{\mathrm{lc}}}\left(C_{\mathrm{ap}}-B P_{\mathrm{lc}}\right)+A Q I_{\mathrm{lc}}$

$A Q I_{\text {ap }}$ is the index for a specific air pollutant (ap), and $A Q I_{\text {ue }}$ and $A Q I_{\text {lc }}$ are the index values for the upper and lower breakpoint (BP) categories, respectively. The $B P_{\text {uc }}$ concentration for each air pollutant is represented by $C_{\text {ap }}$, and the air pollutant upper and lower concentrations at each BP category are represented by $B P_{\text {lc }}$ (Yousefian et al. 2020). With respect to $0-50,51-100,101-200,201-300$, 
301-400, and 401-500 AQI, the AQI is classified into six categories: fine, moderate, bad for vulnerable groups, poor, very harmful, and dangerous. The concentrations are converted into a number within a 0-500 scale (Sharma et al. 2020).

SPSS and Excel are applied in analyzing the data. Comparison of mean, maximum, and minimum daily indices are assessed within a 60-day range. To understand the process of changing the statistical parameters, the maximum AQI for all the studied stations is assessed, and the Excel software is applied to draw the related graphs.

\section{Phase ii: geostatistics and spatial analysis of AQI data}

The spatial covariance or distortion is used to describe the spatial continuity characterization of a given attribute (Kim et al. 2022). Indeed, there are several spatial characteristics of the attribute, such as the distribution of air pollution patterns of continuity and spatial dispersion at different scales. In the present study, the statistical characteristics of the calculated points were used for geostatistical research (i.e., a variogram) and interpolation (i.e., produce raster from calculated points). Furthermore, to apply interpolation techniques and spatial autocorrelation, the Moran index has been used (Nguyen et al. 2022b).

\section{Variogram}

Geostatistics is a type of information that produces quantitative information of natural variables ordered in time and space. Geostatistics is divided into two parts: variography and interpolation (Ogunsanwo et al. 2021, Gagliardi et al. 2021). The frequency distribution of data is very important in terms of its effect on estimation by geostatistics methods. To perform geostatistical analyses, the samples must follow a normal distribution. In this way, we need to perform the normality test, and if the data distribution is not normal, the data are normalized using various methods, so that the accuracy of data estimation increases after the normalization (Qu et al., 2021).

The semivariogram is a statistical variable (spatial insertion) to create input parameters and estimate spatial variability (Koike et al. 2021). The measured distance is a function of the statistical correlation power of the semivariogram. The sierras represent the interval at which the spatial relationship disappears, and the threshold represents the highest variability in the lack of spatial dependence. The semivariogram is half the supposed square interval between the values of paired data $Z(x)$ and $Z(x+h)$ with a delay interval $h$ with which the locations are classified (Molla et al. 2022).
For discrete sampling sites such as those in this study, the function is usually written in Eq. (2):

$\mathrm{Y}(h)=\frac{1}{2 N(h)} \sum_{i=1}^{N(h)}\left[Z\left(x_{i}+h\right)-z\left(x_{i}\right)\right]^{2}$

where $c(h)$ is the half-variance, $h$ is the delay distance, $Z$ is the AQI parameter, $N(h)$ is the number of pairs of locations separated by the delay intervals $h, Z(x i)$ and $Z(x i+\mathrm{h})$ are the values of $Z$ that are in the positions $x i$ and $x i+h$, respectively (Alsafadi et al. 2021, Zhang and Lv 2021).

Because the geostatistics of the model is dependent, a theoretical model must fit the experimental variogram prior to interpolation. Some theoretical models, such as linear, spherical, exponential, and Gaussian models, can describe the semivariogram (Cao et al. 2022; Bauwelinck et al. 2022). Indeed, when modeling a variogram, the model that has the least amount of residuals should be chosen.

\section{Interpolation}

By applying the geographical data and environmental information and integrating them with the Air Pollution Monitoring Center data, the distribution patterns and spatial analysis are designed and mapped. In this study, the assessments include the spatial analysis of the concentrations of the air pollutants (the pollution index) as well as the process of their changes in the time periods of recording the first case of COVID-19 during the beginning and end of quarantine in Tehran. Applying the spatial and geostatistical methods is common in assessing the distribution of air pollution in similar studies of this field. In this study, mapping the average AQI of the 2017-2020 period and the changes thereof are assessed. By adopting this method, it is possible to accurately distribute air pollution at different times in locations with no data. The radial basis functions (RBF), empirical Bayesian kriging (EBK), global polynomial interpolation (GPI), local polynomial interpolation (LPI), inverse distance weighting (IDW), kernel smoothing estimation (KSE), and diffusion kernel interpolation (DKI) are applied here according to validation, and the output is selected for each studied time period (Hossain et al. 2022; Azizsafaei et al. 2021).

\section{Radial basis function}

This is an algorithm for interpolating a surface with the least curvature using sampling-interpolation points. The generated surface must pass through each measured point, and the radial basis function (RBF) predicts values that are identical to those measured at the same point. The predicted values can differ from the measured values' maximum and minimum (Nguyen et al. 2022a). This is done by applying a set of low-order local polynomial insertions to a set of adjacent 
interpolation points that pass within the sample points. This method gives better results for surfaces with a relatively mild slope (e.g., the condensation of water level contamination). When the surface values change dramatically over short distances, RBF is ineffective (Plack et al. 2022).

\section{Empirical Bayesian kriging}

In the field of air pollution science, empirical Bayesian kriging (EBK) is notable widely used. EBK is a geostatistical interpolation approach that simplifies the process of creating a reliable kriging model. In EBK, it is assumed that for the semi-variable interpolation region, the actual graph is estimated and the linear prediction with spatial attenuation is variable. Other methods necessitate manual parameter adjustments, but EBK calculates these parameters automatically using subsetting and simulation processes (Sun et al. 2022). As a result, a nonstationary algorithm for spatial interpolating geophysical corrections has been developed. When the coverage is good, this algorithm extends local trends and admits it to bend to a previous background when the coverage is insufficient (Ahamed et al. 2022).

\section{Global polynomial interpolation}

The sample points are fitted with a polynomial formula by global polynomial. The sampled data points are fitted with a smooth surface by GPI. GPI is the only geostatistical analytics method that does not utilize neighborhood or search height. GPI creates a surface using a variety of formulas, each of which is tailored to a specific neighborhood. The global polynomial surface evolves over time and captures the data's coarse scale patterns. GPI is conceptually similar to placing a piece of paper between highlights (Beauchamp et al. 2018).

\section{Local polynomial interpolation}

Local polynomial fits the local polynomial using points only within the specified neighborhood instead of all data (Alsafadi et al. 2021). The LPI uses the center of each region as a forecast for each place, after fitting smaller areas of overlap with the sample points. Neighborhoods can then overlay, and the area value in the center of the neighborhood can be determined as the prognosticated value. LPI has the ability to create levels that catch short-range changes (Farzin et al. 2020).

\section{Inverse distance weighting}

IDW, based on close understood locations, is the most comprehensive method for air pollution interception techniques. The presumption that close things are more similar than those that are far apart is explicitly supported by IDW interpolation. The weight of the interpolation points is proportional to their extent from the interpolation point. It weighs the points closer to the prediction location greater than those farther away, hence the name inverse distance weighting. In fact, the known sample points are implicit to be self-governing from each other (Atta 2020).

\section{Kernel smoothing estimation}

In statistics related to nonparametric, the points recognized in the nucleus density estimation are viewed as the achievement of a possibility level (Brindha 2021). This method is used to detect accident points (automatically records the value for each point), and then it calculates the density using numerical statistical algorithms. In other words, the underlying principle of this method is that it defines the density of the nearest neighboring accident points by first calculating the distance of another accident from the initial reference accident point. In addition, KDE is a manner for indicating the possibility density at any location, for example, constructing a possibility density level based on locations (points).

The "cross-validation" method is applied for validation to determine which approach offers the best interpolation. A cross-validation technique was used to assess and analyze the performance of different interpolation techniques. The main criterion to select cross-validation is the root square error (RMSE), which can calculate fixed points (Draper et al. 2013; Bosboom et al. 2020).

\section{Spatial autocorrelation (Moran's index)}

This index is widely used to determine how clustered, random, or fragmented a spatial pattern is. The global spatial autocorrelation (global Moran's index) calculates the average degree of spatial autocorrelation for emissions and air quality datasets, while the local spatial autocorrelation (local Moran's index) identifies the position and form of contaminants and air quality variables (Zhao et al. 2019, 2020). To calculate the spatial autocorrelation, first, the $z$-score and $p$-value are calculated, and next, the significance of the index is evaluated. Moran's index is calculated through Eq. (3).

$I=\frac{\sum_{i=1}^{n} \sum_{j=1}^{n} W i . j\left(X_{\mathrm{i}}-\bar{X}\right)\left(X_{\mathrm{j}}-\bar{X}\right)}{\left(\sum_{i=1}^{n} \sum_{j=1}^{n} W i . j\right) \sum_{\mathrm{i}=1}^{\mathrm{n}}\left(X_{\mathrm{i}}-\bar{X}\right)^{2}}$

where $n$ denotes the number of zones, $X_{\mathrm{i}}$ and $X_{\mathrm{j}}$ denote the intensity values in positions $i$ and $j$, and $X$ denotes the mean vector. The global spatial autocorrelation change is within the -1 and +1 range. If the spatial autocorrelation values are 
significant and greater than zero, the spatial autocorrelation is positive and clustered, otherwise negative and scattered. The $Z(I)$ indicates a random pattern in the value of observations. In general, the spatial autocorrelation is subject to the values of the $z$-score, which means that the positive score values indicate a high-value clustering and the negative values indicate a low precipitation spatial clustering (Jiang et al. 2021). To assess the spatial distribution of AQI, Eq. (4) is applied in estimating the local spatial autocorrelation.

$I=\frac{\left(X_{\mathrm{i}}-\bar{X}\right)}{S^{2}} \sum_{i=1 . j \neq 1}^{n}$ Wi.jWi.j( $\left.X_{\mathrm{i}}-\bar{X}\right)$

$W i . j$ is the weight of the spatial within phenomena $i$ and $j$, where $X_{i}$ is the root of $I$ and $X$ is the average of the concern.

\section{Results}

After collecting and reviewing data from the active stations in Tehran, preprocessing was performed on the data of the study area, which included the replacement of sensor and missing data. Also, a nonparametric test was used to determine the normality of the data. The information of the relevant parameters is extracted on a daily basis, and a dataset of the pollution concentration and air quality was generated. Table 1 displays the minimum, maximum, and average AQI values, as well as the number of unhealthy days with $A Q I=100$ over a 60 -day period. On average, the level of pollution was higher in the period 2017 to 2018, compared with 2019 to 2020, where the lower volume of pollution and number of unhealthy days was counted in 2020, due to the impact of weather parameters, in this case, rainfall. The weather conditions, quarantining, and region location are the three main factors of air quality in Tehran during the three time periods studied. Although it is difficult to separate these three factors, the assessment of the level of pollution during quarantine conditions compared to previous years provides useful information on the management of urban air quality.

As shown in Table 2 and Fig. 1, in general, the rate of pollution contamination in April 2020 in the 60-day COVID-19 quarantine period has not changed significantly compared to the same period in 2019; however, pollutants such as PM2.5 have increased dust in Tehran. The prevalence of COVID-19 and the announcement of COVID-19 quarantine conditions in Iran coincided with Nowrooz holidays (New Year holidays in Iran), and during this period, many industries reduce their activities, and the traffic volume in Tehran decreases, leading to the average volume of pollutants. Despite the fact that this period is short, taking into account the number of healthy and unhealthy days and the volume of different pollutants per day in the COVID-19 quarantine period compared to previous years, we can conclude that pollution has decreased during the quarantine period due to a decrease in industrial activities and urban traffic. Moreover, some pollutants, such as $\mathrm{SO}_{2}, \mathrm{O}_{3}$, and $\mathrm{CO}$, are reduced due to the decline in traffic and industrial activities.

In all the tables, the days showing the level of pollution and the sources of pollution are separated. This means that the recorded information was received by a station and then classified according to the AQI standard. Next, the cause of the pollution was identified. However, depending on the location of the station and its conditions, all the days with high pollution may be in the same class, and other days may have a good distribution or "zero" condition which, for example, indicates the absence of "Good Day" at a specific time and location (station). More specifically, in Table 2, in 2017, there was no day in the "Hazardous" status throughout the year, and only 3 days were very unhealthy. Thus, zero shows the number of class days at a station.

The share of each pollutant is shown separately for each of the 13 stations studied in Fig. 3. Overall, pollution indices such as $\mathrm{NO}_{2}, \mathrm{O}_{3}$, and $\mathrm{CO}$ have sharply decreased in stations at various times, while the share of suspended particles has increased. This variation does not indicate an increase in pollution, but rather a mixture of pollutants. Due to the decrease in vehicle traffic, the University of Tehran's station, which is the city's central station and has the most vehicle traffic, has shown different amounts and combinations of the pollutants during the COVID-19 quarantine period. This can be generalized to all the stations. The time trend of 2020 compared to 2019 indicates a decrease in the share of important pollutants. Changes in the pollution rate during the study period can be due to reduced urban traffic, small industrial activities, and dust mites of urban and industrial origins. Although pollution has declined in most regions during the COVID-19 quarantine period, the PM2.5 rate has not decreased significantly, which might be because of natural origins such as dust.

Applying geostatistical technique, the spatial structures between the data are first examined using variogram analysis. The condition for using this analysis is the normality of the data that we normalized in the previous section. The result of this test is shown in Table 3, which shows that the data are well normal. To spatially connect a variable using a variogram, it is essential to calculate the mean of the squares of the difference between two points separated by a known distance $h$ and plot in front of $h$ (Seyedmohammadi et al. 2016).

The AQI variogram describes spatial dependencies and builds mutual understanding about the manners that affect its distribution partially. According to Fig. 3, a descriptive model with a more coefficient of measurement and a $C 0 /$ $(C+C 0)$ ratio corresponds well to the semi-variance. Compared to other models, higher R2 and lower RSS, this model 
Environmental Science and Pollution Research (2022) 29:38505-38526

38513

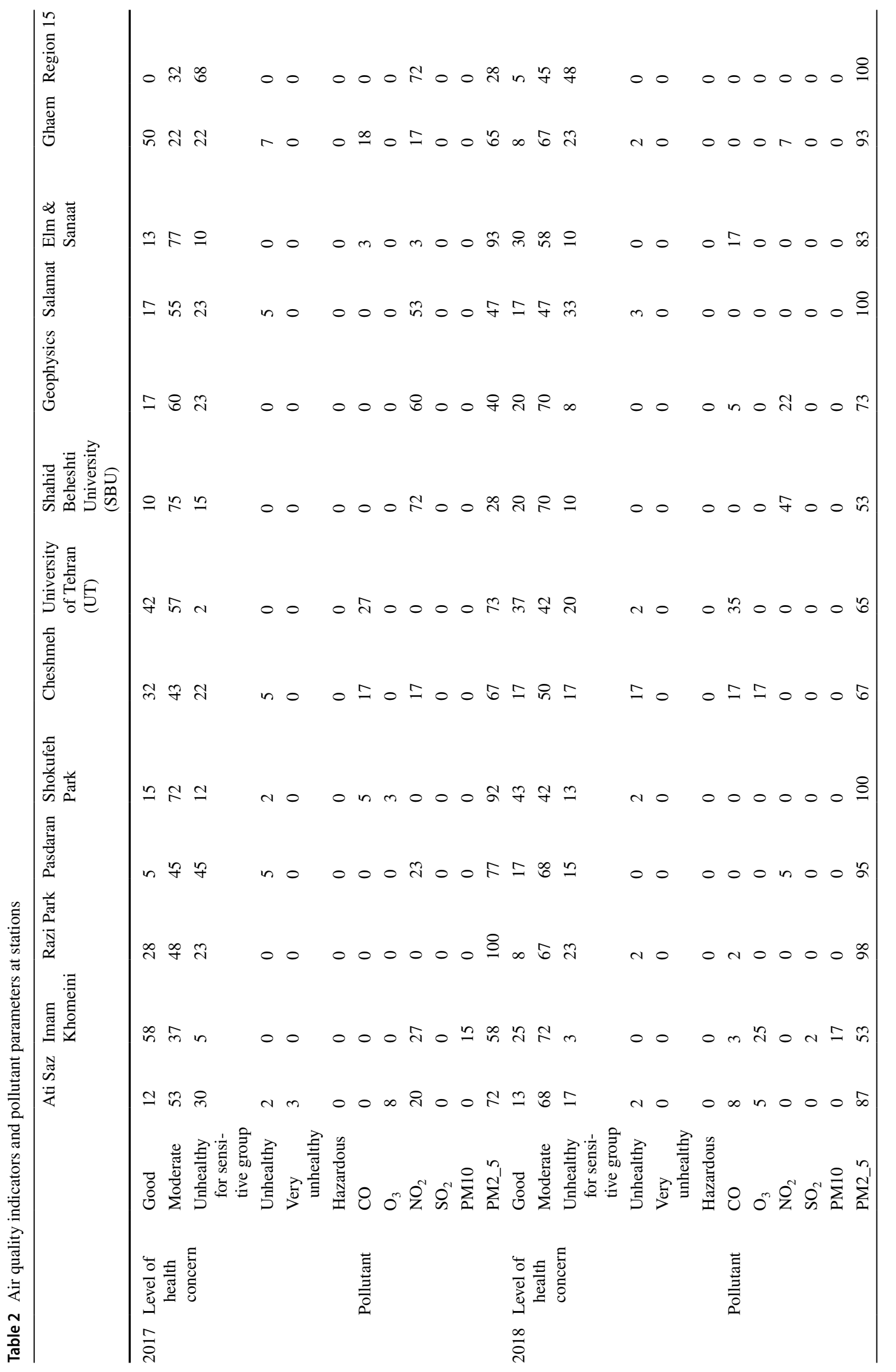

Springer 


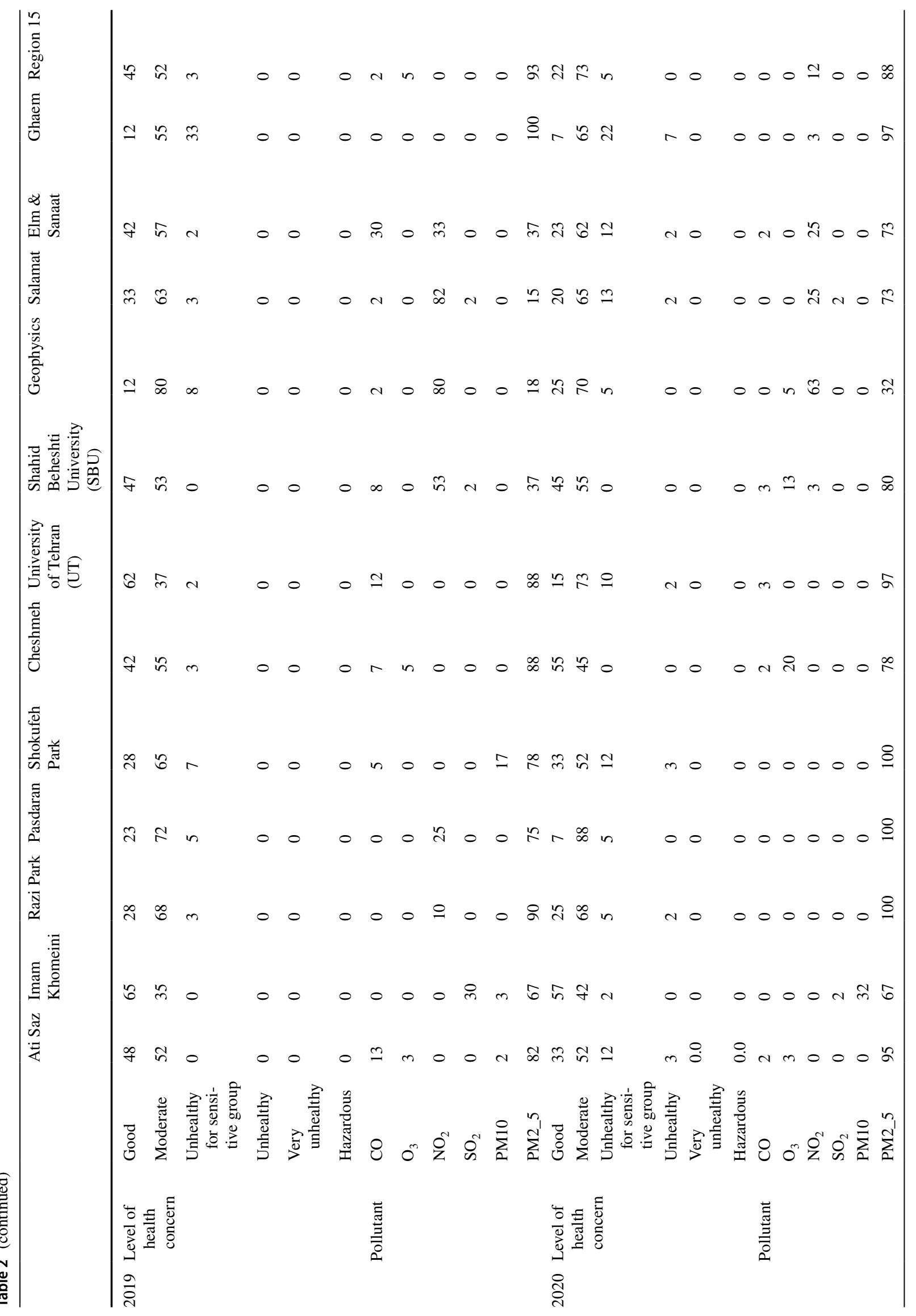


Fig. 3 The contribution of each pollutant to air pollution
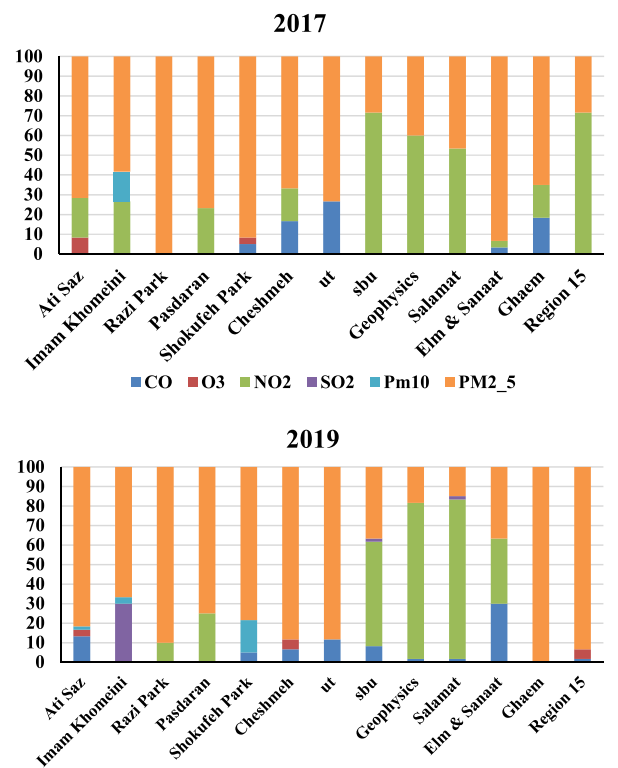

$\llbracket \mathrm{CO} \backsim \mathrm{O} 3 \approx \mathrm{NO2} \backsim \mathrm{SO}=\mathrm{Pm} 10 \backsim \mathrm{PM2} 5$

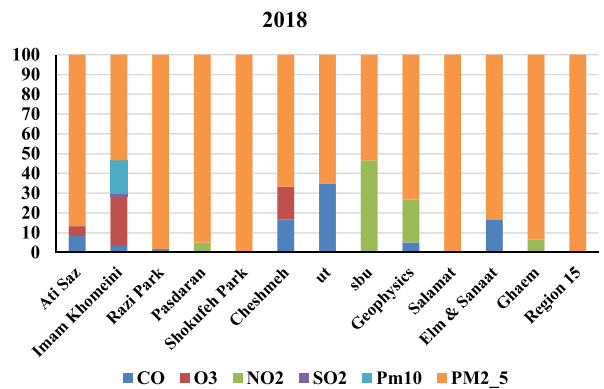

2020

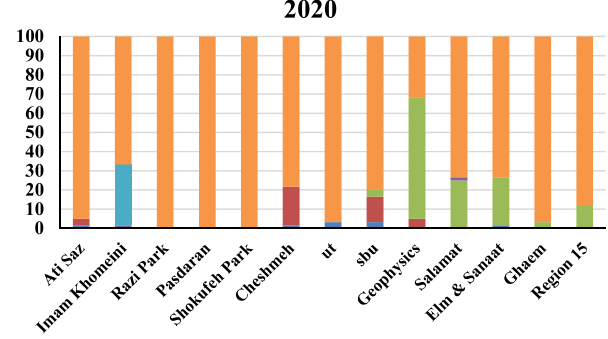

$\backsim \mathrm{CO} \backsim \mathrm{O} 3 \backsim \mathrm{NO} 2 \backsim \mathrm{SO} 2 \backsim \mathrm{Pm} 10 \backsim \mathrm{PM} 25$

implemented in an experimental half variable shows that it

The comparison of models shows that almost in all the

Table 3 Descriptive statistics of data used for interpolation

\begin{tabular}{lclcllll}
\hline Year & Minimum & Maximum & Mean & SD & CV (\%) & Skewness & Kurtosis \\
\hline$A Q I_{\text {AVG }}(2017-2019)$ & 57.17 & 87.59 & 71.28 & 9.83 & 96.8 & 0.04 & -1.2 \\
$A Q I_{\text {AVG }}(2020)$ & 54.02 & 87.18 & 67.97 & 8.76 & 76.81 & 0.4 & 0.09 \\
Changes in the $A Q I_{\text {AVG }}$ & -19.79 & 16.22 & -3.32 & 9.03 & 81.6 & 0.36 & 0.22 \\
\hline
\end{tabular}

$S D$ standard deviation, $C V$ coefficient of variation

Table 4 Characteristics of fitted models on the variogram

\begin{tabular}{|c|c|c|c|c|c|c|c|}
\hline Year & Model & $C_{0}$ (nugget effect) & $C+C_{0}($ sill $)$ & Effective range (m) & $C_{0} /\left(C+C_{0}\right)$ & $R^{2}$ & RSS \\
\hline$A Q I_{\mathrm{AVG}}(2017-2019)$ & Spherical & 0.1 & 101.7 & 7760 & 0.313 & 0.287 & 13,435 \\
\hline$A Q I_{\mathrm{AVG}}(2020)$ & Spherical & 54 & 116.1 & 41,100 & 0.535 & 0.129 & 5099 \\
\hline Changes in the $A Q I_{\mathrm{AVG}}$ & Linear & 95.88 & 95.87 & $15,770.92$ & 0 & 0.65 & 7074 \\
\hline
\end{tabular}

is the most suitable model among other models. The nugget impact ratio for the variables is around 0.25 and 0.75 , as shown in the outcomes of the variogram (Table 4 and Fig. 4), and the most appropriate model fitted to AQI for 2020 is Gaussian (Arora 2018).

The data applied in the geostatistics, after normalization and variography in GS $+\mathrm{s} / \mathrm{w}$, are interpolated by different models and then applied in root mean square (RMS) evaluation. In this study, RBF, EBK, GPI, LPI, IDW, KSE, and DKI were used to estimate AQI. By applying RMS, the interpolation models can be compared to find the most appropriate model. If the value of this RMS is smaller, it indicates more accuracy in estimation. The accuracy and precision of interpolation models are compared in Table 5. models, the RMS were close to each other. However, due to the fact that an interpolated raster must be selected for analysis each year, the interpolation with the least error was selected. For the average of 2017 and 2019, the IDW model with EBK and KSE presented almost similar results, and the LPI and DKI had the same RMS of 10.23 and 20.24, but the RBF model had a lower error coefficient. This model was selected for the 2017 and 2018 average interpolation. In 2020, almost all the models had an RMS between 3.4 and 9, except for the GPI model, in which the IDW model was chosen because of the lower RMS. However, the IDW model was chosen to calculate the difference in variation and the quarantine effect, which is due to the fact that this model has a lower RMS than the other models. Although 

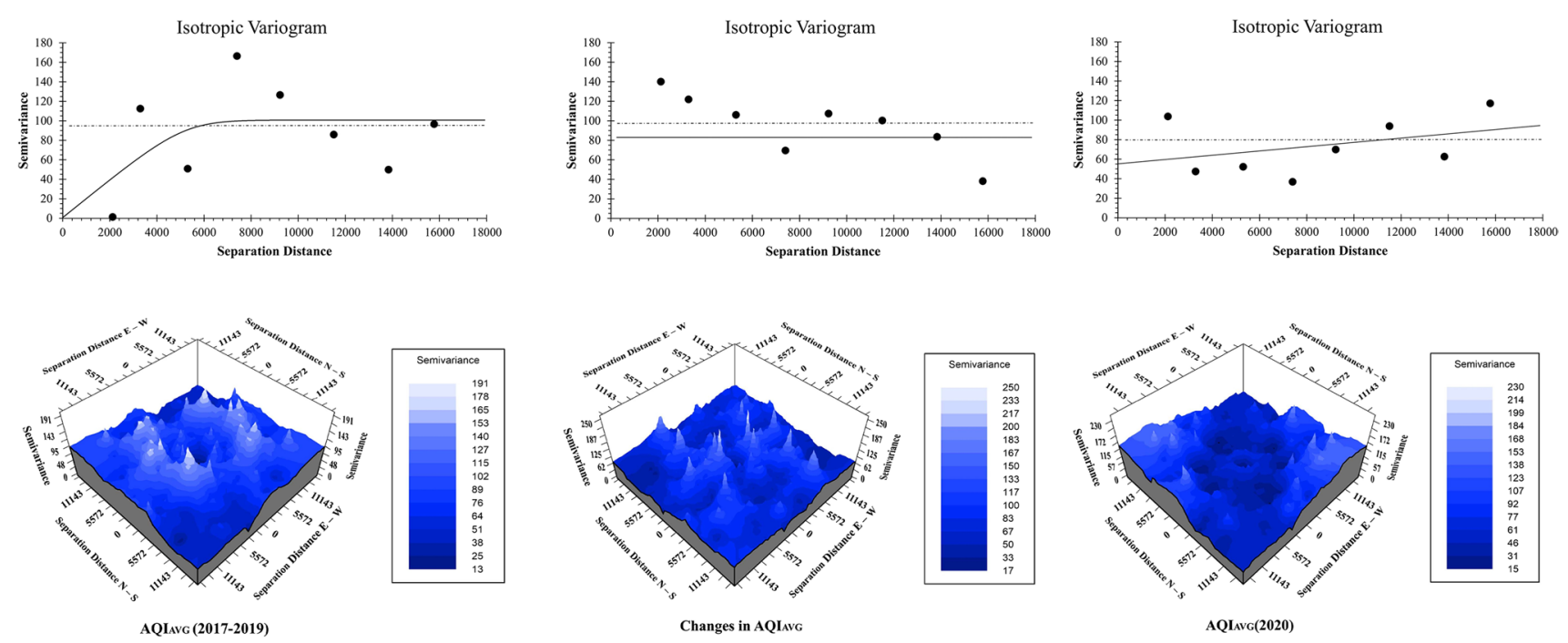

Fig. 4 Semivariograms of AQI

the IDW RMS was close to the LPI, the others had higher

transportation and only using personal cars, which lead to

Table 5 Comparison of different Interpolation models using (RMS)

\begin{tabular}{|c|c|c|c|}
\hline \multirow[t]{2}{*}{ Interpolation method } & $A Q I_{\mathrm{AVG}}(2017-2019)$ & $A Q I_{\mathrm{AVG}}(2020)$ & $\begin{array}{l}\text { Changes in the } A Q I_{\mathrm{AVG}} \\
(2017-2019 \text { and } 2020)\end{array}$ \\
\hline & Root mean standard & Root mean standard & Root mean standard \\
\hline Inverse distance weighting (IDW) & 9.42 & 8.48 & 9.25 \\
\hline Global polynomial (GPI) & 10.43 & 10.16 & 11.12 \\
\hline Radial basis functions (RBF) & 8.91 & 8.877 & 10.09 \\
\hline Local polynomial (LPI) & 10.23 & 9.06 & 9.4 \\
\hline Empirical Bayesian kriging (EBK) & 9.77 & 8.58 & 9.9 \\
\hline Kernel smoothing (KSE) & 9.84 & 8.73 & 10.31 \\
\hline Diffusion kernel (DKI) & 10.24 & 9.02 & 9.79 \\
\hline
\end{tabular}

RMS. Hence, for this purpose, the RBF method was applied for AQIAVG (2017-2019) interpolation, and the IDW model was applied for AQIAVG (2020) interpolation. Changes in AQI are shown in Figs. 5, 6, and 7.

Figure 5 shows the high AQI index but does not indicate the contamination factor. Therefore, the reason for the increase in the index in the southern areas of the city is the presence of polluting industries. As shown in Fig. 3, in the stations of region $15, \mathrm{NO}_{3}$ and $\mathrm{O}_{3}$ and dust are the main factors increasing the index. Furthermore, with the closure of all businesses from 2017 to 2019 during the holidays, traffic has sharply decreased and as a result, pollution has decreased. However, as shown in Fig. 6, such situation is still prone to factory pollution and dust, due to the proximity of susceptible areas. In District 6, which is the center of the city, the level of pollution has increased slightly. The reason for the increase in pollution and the index is not using public heavy traffic in these areas. Districts 6, 7, 8, and 4 have a large population and urban infrastructure such as hospitals, which has increased the traffic in these areas. Figure 7 shows the difference between the indicators, which is an expression of the increase in the index in the city center and the main roads related to it. In the southern areas, due to the closure of factories and the decrease in entry and exit of the province, the index has decreased.

The interpolation of the results indicates that in the years 2017-2019, the highest AQI rate was in the center of the city, due to traffic congestion, which was not influenced by COVID-19 quarantine program. A decline in the AQI in the south and north of the city was observed, mainly due to the curfew and the closure of university centers and polluting industries in the south of the city. Based on AQI interpolation, changes are felt in southern regional pollution. Air pollution is a problem in Tehran's southern districts 


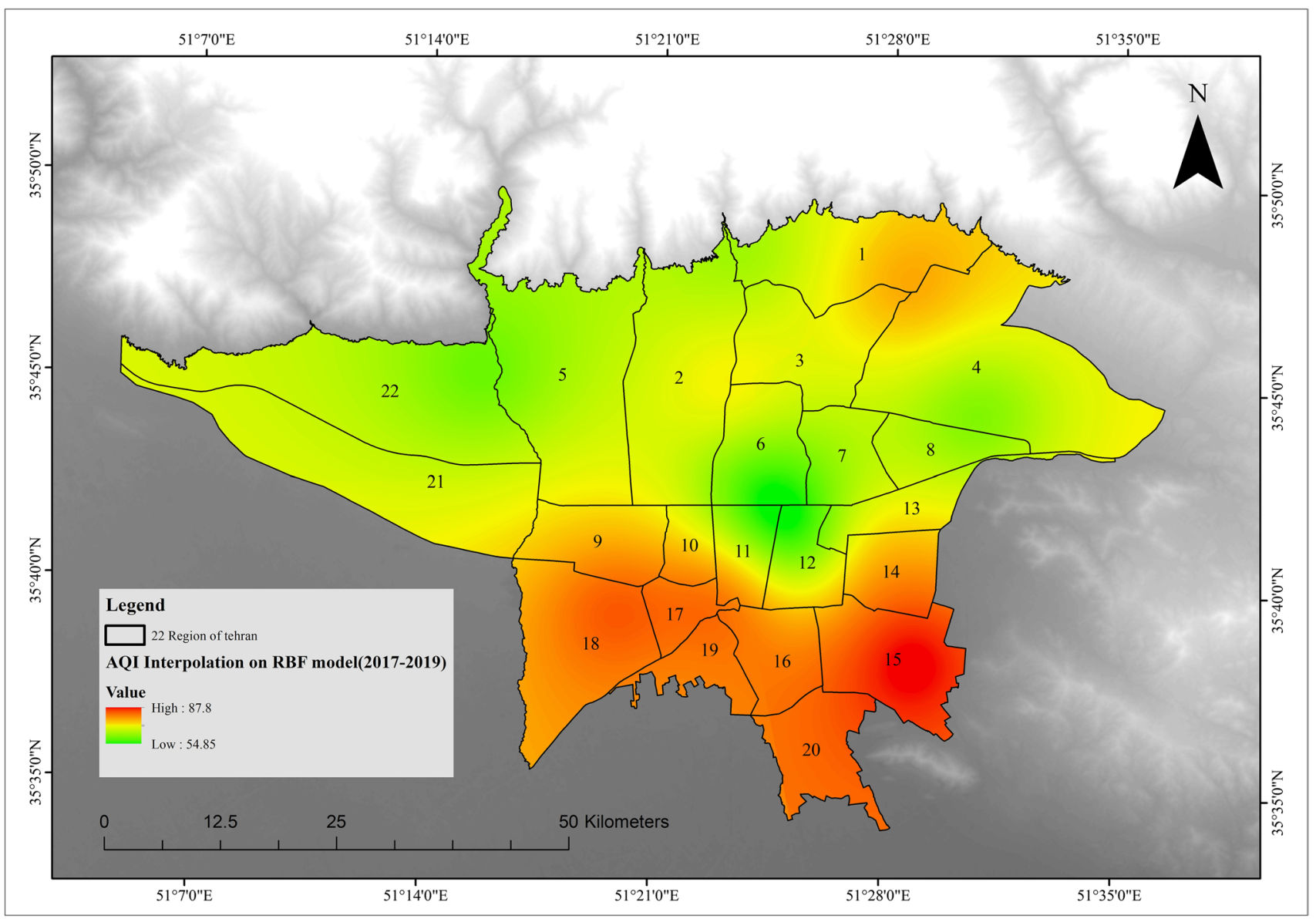

Fig. 5 AQI interpolation from 2017 to 2019 based on the radial basis function (RBF) model

due to factory operations and heavy traffic, while during the COVID-19 quarantine, the activities are reduced, as well as the volume of industrial pollution. In the center, air quality is mostly affected by the heavy traffic which moves throughout the city during the quarantine period; thus, there is no decrease in air quality despite the quarantine. It is worth noting that the interpolation of the city based on the volume and type of pollution is essential in air quality management in the post-COVID-19 period.

\section{Spatial autocorrelation (global Moran's index)}

To extract the spatial statistics by applying zonal statistical command, first, the volume of statistics for 22 regions of Tehran should be extracted, separately. For this purpose, the spatial autocorrelation of the indicators should be extracted according to the physical features of each region. The global Moran's index outputs are presented in their graphical and numerical sense in Fig. 8 and Table 6, where the graphical output shows the clustered or scattered data. In general, data with a Moran's index value close to +1 have a spatial autocorrelation and cluster pattern, whereas data with a
Moran's index value close to -1 are fragmented and dispersed. The null hypothesis in this index suggests that no spatial clustering occurs among the volumes of the elements associated with the appropriate geographical features. When the $p$-value and approximate $z$-value are very small in this method, the absolute value is very high (the tax is within the confidence range), and the null hypothesis can be rejected. As observed in Table 6, Moran's index is 0.613 and 0.488 , respectively, for $A Q I_{\mathrm{AVG}}(2017-2019)$ and $A Q I_{\mathrm{AVG}}$ (2020), and 0.37 for the change in AQI.

The evaluation of the volumes obtained through the significant threshold in a significant manner reveals that the estimated values of Moran's index for the three time scales examined at 0.01 alpha are significant, which indicates no spatial clustering. It is concluded that both AQIs for each year and its changes follow a structured spatial pattern in the study area and are not distributed in a random manner.

\section{Spatial autocorrelation (local Moran's index)}

Global Moran's index specifies only one pattern. Therefore, this index is applied in assessing the spatial 


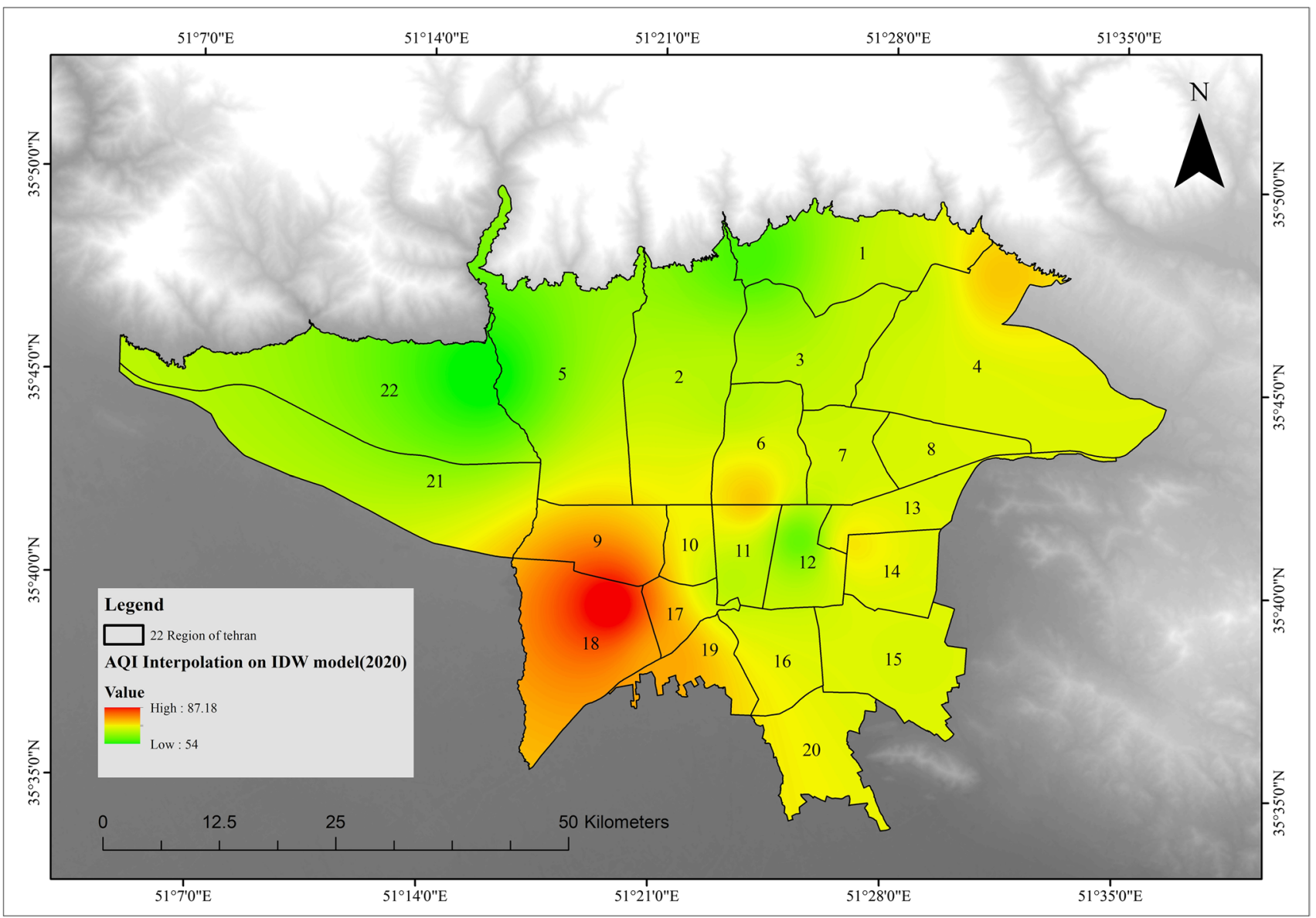

Fig. 6 AQI average interpolation since 2020 based on the inverse distance weighting (IDW) model

distribution of the pattern governing the AQI. The results of the significant local Moran's maps (Fig. 8) show the AQI clustering. If the volumes in Eq. (2) are positive, the phenomenon is surrounded by similar effects, implying that the phenomenon or the AQI is part of that noncluster. The obtained volumes of this statistic are calculated within the standard score and the $p$-value and can be interpreted and analyzed. In addition to $z$ being positive and $p$ being significant, the Moran index was also significant. As a result, the introduced pattern is clustered in the form of a cluster pattern for the reasons described (hotspot centers are surrounded by cloud spots). High-high cluster $(\mathrm{HH})$ represents a cluster class of high value which has a positive spatial covariate at $99 \%$ significance level, while low-low cluster (LL) represents a cluster class of low value which has a negative spatial covariate at $99 \%$ significance level. High-low outlier (HL) is a non-cluster class where a positive volume of negative values is confined, while in low-high outlier (LH), a negative volume of positive values is confined at 5\% significance level. Table 7 and Fig. 9 show different patterns of the local Moran's air quality in the time scales studied.
Figure 9 shows the clustering of areas, indicating that during the same quarantine period (Nowrooz holiday), from 2017 to 2019, region 7 and in the quarantine period of districts 17,9 , and 18 as hotspots are high-risk areas for pollution. Besides, zones 6 and 7 have been introduced as hotspots due to the increase in pollution during the quarantine period, and zone 20 has become a cold spot.

Getis analyses are used to identify key regions and changes in AQI over time. The results of Getis-Ord Gi statistics have been used to identify key points such as hotspots, the increase in AQI (cold spots), and the decrease in AQI, which are shown in Fig. 10 (95, 90, and 99\% confidence levels). Furthermore, zones 15 and 16 with $99 \%$ confidence and zone 20 with $95 \%$ confidence were calculated as cold spots, while zones 6 with $99 \%$ confidence, zones 7 and 11 with $95 \%$ confidence, and zones 8 and 2 with $90 \%$ confidence were calculated as hotspots.

According to the pollution center, regions 2, 6, 7, and 8 , which are on the same spots, in addition to showing the effect of car traffic on air quality, probably indicate the effects of climatic elements, like the wind in region 6 , and the spread of pollution therein to other surrounding 


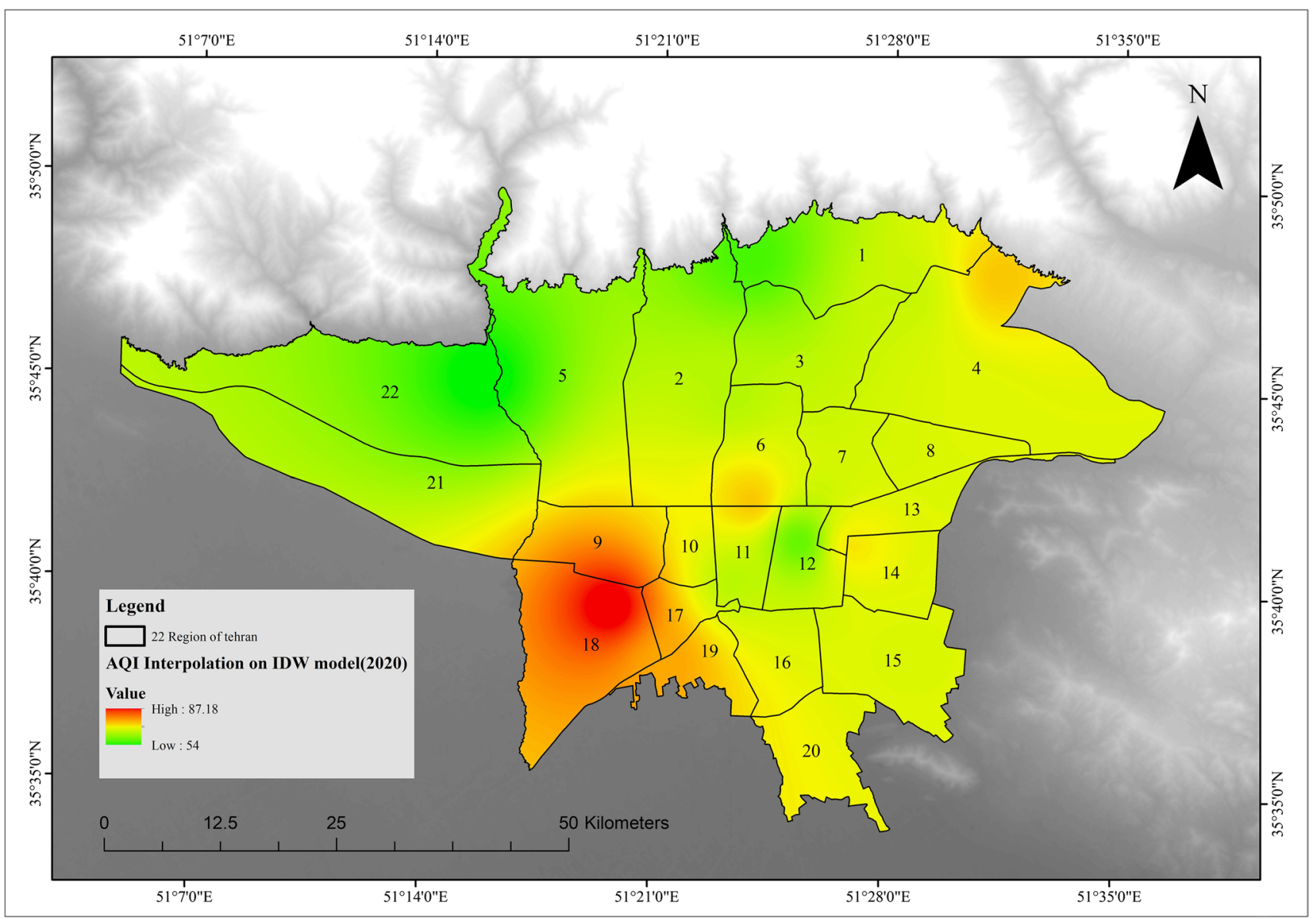

Fig. 7 Ranking changes in the 2020 AQI compared to the average air quality index from 2017 to 2019 based on the IDW model

regions. The results of the study indicate that commercial regions, such as regions 5 and 6 , have the highest pollution during the COVID-19 quarantine period. Quarantine has been more effective in closing factories than urban small businesses.

To calculate the index changes in the study region, the maximum intensity of AQI parameters (except for $\mathrm{SO}_{2}$ and PM2.5) for all the stations is assessed (Table 8). Figure 11 shows that polluted days caused by PM2.5 have a sharp increase, which was at the beginning of the curfew on March 2. The AQI slope shows a further decrease compared to previous years. This rate followed a descending pattern until March 27, when the maximum intensity of the fixed trend index increased until April 12, when the quarantine ended, and then increased to 18 days after the air quality index restrictions were lifted.

The declining trend of $A Q I_{\max }$ within 2017-2019 and 2020 is evident from February 20, which is in the period before and after the New Year in Iran, but the main difference is on March 10, the beginning of the quarantine, which is probably due to reduced industrial activities and traffic in Tehran.

\section{Discussion}

In this study, changes in air quality, the volume of pollutants affecting the city of Tehran as one of the most populous cities infected with COVID-19, and the degree of interaction of this virus with air pollution and vice versa are assessed. During the COVID-19 quarantine season, the AQIs improved significantly; $\mathrm{SO}_{2}, \mathrm{NO}_{2}$, and $\mathrm{O}_{3}$ emissions added fewer pollutants to the air; and the number of contaminated days decreased relative to previous years. Although the air quality index increased in 2020 compared to 2019 (in 2019, there was more rain and wind), the annual mean changes are noticeable compared to the same periods, i.e., the New Year holidays in Iran which led to the normal closure of most of the jobs and industries and reduced traffic in the city. The findings of this research indicate that air pollution problem is related to the economic, social, and political situations, and its control requires the participation of all communities. Assessing the changes in pollution before and after the COVID-19 quarantine period separates regions affected by the pollution emitted from factories and vehicles. 
Table 6 Spatial autocorrelation (global Moran's index) values for the study area

\begin{tabular}{llllll}
\hline Time period & Moran's index & Expected index & Variance & $p$-value & $z$-score \\
\hline$A Q I_{\mathrm{AVG}}(2017-2019)$ & 0.613233 & -0.047619 & 0.030440 & 0.000152 & 3.787753 \\
$\left.A Q I_{\mathrm{AVG}}\right) 2020($ & 0.488177 & -0.047619 & 0.027644 & 0.001270 & 3.222571 \\
Changes in the $A Q I_{\mathrm{AVG}}$ & 0.371149 & -0.047619 & 0.025940 & 0.009320 & 2.600073 \\
$(2017-2019$ and 2020) & & & & & \\
\hline
\end{tabular}
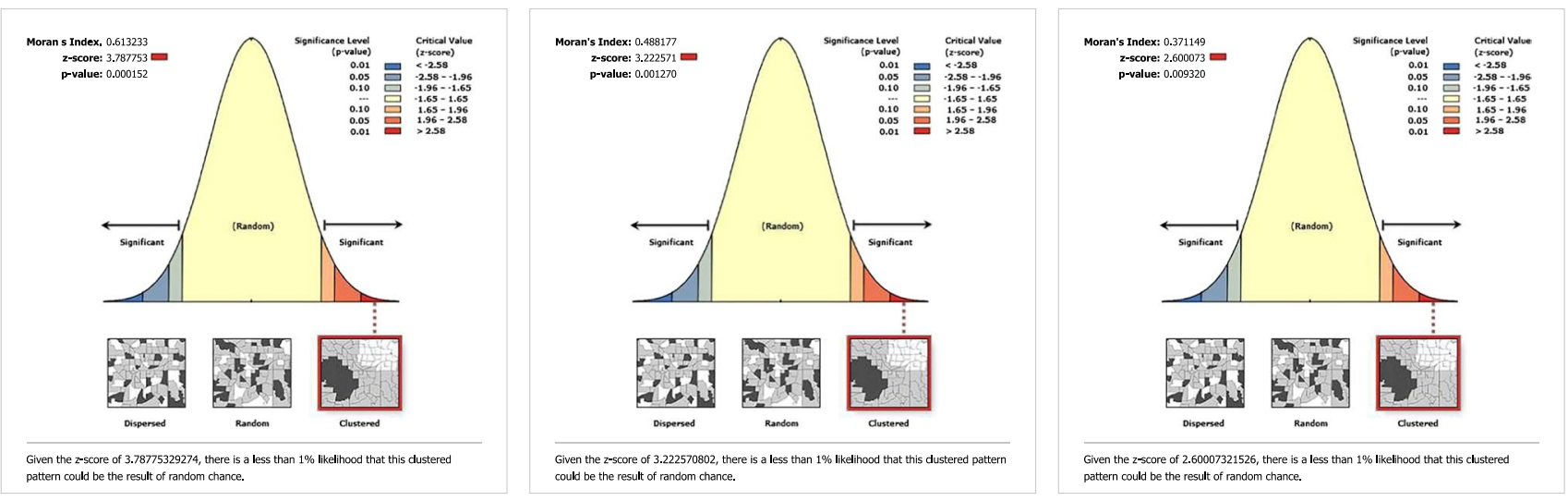

Fig. 8 Spatial autocorrelation (Moran's index) graphic diagram for the study area

The obtained findings are, on the whole, entirely compatible with relevant research. According to the studies by Mao et al. (2020), Venter et al. (2020), and Yousefian et al. (2020), dry air causes thermal inversion, which stops vertical contaminants from spreading and increasing their accumulation. Furthermore, wind speed can help minimize emissions. Briz-Redón et al. (2021) discovered that very low wind levels are associated with the raising air deposition by reducing PM. The formation of pollutants, particularly PM, can have a positive impact on high pressures. According to Rahman et al. (2021), suspended particles cannot scatter and accumulate properly, contributing to high particle loads in the atmosphere. The results indicate that the AQI index has a positive autocorrelation in Tehran, which is quite consistent with the findings of Xiong et al. (2020), Filonchyk et al. (2020), and Chen et al. (2020a, b, c). They looked at the COVID-19 epidemic's geographic statistics and contributing factors in Hubei Province, China. According to our study, significant improvement in air quality was also found in cities that implemented measures, other than lockdowns, to prevent the spread of COVID-19. These improvements in AQI have been observed in different countries experiencing COVID-19, including the USA (Berman and Ebisu 2020a, b; Pan et al. 2020), Italy (Zoran et al. 2020), and India (Kumari and Toshniwal 2020; Sharma et al. 2020).

Despite the reduction in some pollutants during the quarantine period, it is important to note that afterward, the volume of pollutants increased, which is probably due to the removal of some regulations like the traffic plan to prevent people from using public transport. Although COVID-19 has reduced global economic growth, it has had a positive impact on the environment, but it is likely that in the post-COVID19 period, politicians and beneficiaries will seek to offset economic growth, and there will be an increase in industrial
Table 7 Areas covered by the pattern obtained from local Moran's analysis

\begin{tabular}{llll}
\hline Type of autocorrelation pattern & \multicolumn{2}{l}{ Covered areas } \\
\cline { 2 - 4 } & $\begin{array}{l}\text { Changes in the } A Q I_{\mathrm{AVG}} \\
(2017-2019 \text { and 2020) }\end{array}$ & $\left.A Q I_{\mathrm{AVG}}\right) 2020($ & $A Q I_{\mathrm{AVG}}(2017-2019)$ \\
\hline High-high cluster pattern & 6,7 & $9,17,18$ & 7 \\
Low-low cluster pattern & 20 & 21 & - \\
High-low outlier pattern & - & - & - \\
Low-high outlier pattern & - & - & - \\
No significant pattern & Other areas & Other areas & Other areas \\
\hline
\end{tabular}




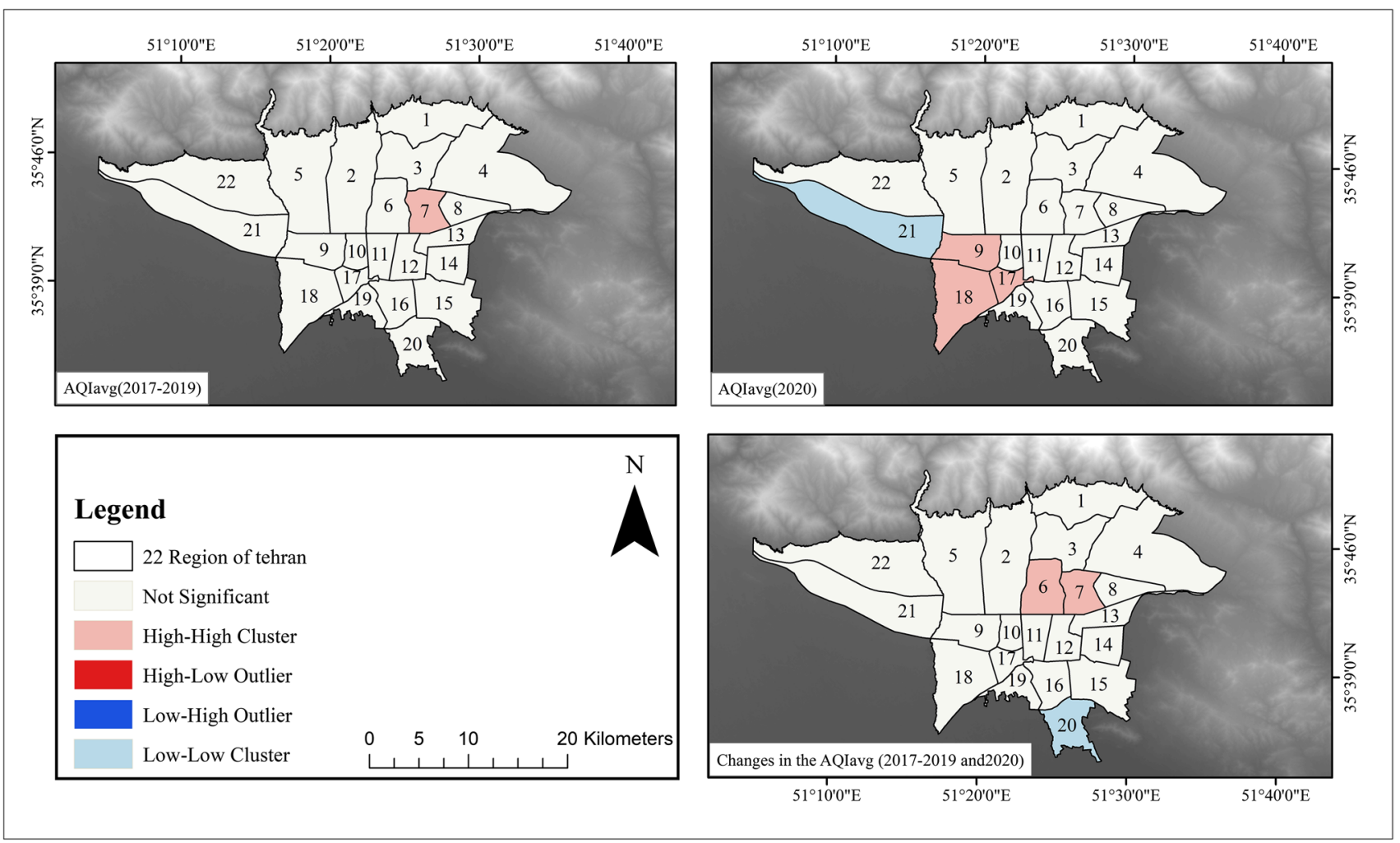

Fig. 9 Distribution of local Moran's pattern for air quality index

and urban pollution. It is necessary to study the effects of the first phase of COVID-19 on the environment comprehensively, during and after COVID-19, in a careful manner. According to previous studies, microorganisms are transmitted by airborne pollutants that pose a high risk to patients with respiratory infections and provide conditions for the invasion of pathogens into humans (Horne et al. 2018; Xie et al. 2019). The highlight of the relationship between pollution levels and the impact of weather conditions on COVID19 emissions is that to date, July 8, 2020, 2 months have passed since the end of COVID-19 quarantine in Iran, and air temperature and pollution levels have increased. However, 200 daily deaths in Iran have been reported during the COVID-19 epidemic (Iran Health Organization 2020). According to Wang and Su (2020), by reviewing the studies run in the past few months, it was found that measures like COVID-19 quarantine and protecting people from becoming infected have an affirmative impact on the environment. The researchers (Ogen 2020) found that 78\% of COVID-19 losses occurred in areas of northern Spain and Italy with high NO2 concentrations that could affect the role of airborne flow in transmitting the virus (Zhu et al. 2020). They confirmed the link between air pollutants and rising condensation of pollutants as the number of people infected with COVID-19 increased (Muhammad et al. 2020; Sood and Sood 2020; Kakol et al. 2020). By examining satellite images and data from contaminated regions, they show a $30 \%$ reduction in air pollution in these regions (Ahmadi et al. 2020). Examination of parameters like population density and climatic factors shows that the effect of high population density and high humidity on COVID-19 emission is positive.

City interpolation based on the volume and type of pollution is essential in air quality management in the post-COVID-19 period. The scale of the cities and the events that take place in them have a significant influence. Transportation, agriculture, and manufacturing have larger human impacts (combustion, automobile exhaust, etc.) in major cities. These results are in line with those of Mahato et al. (2020), Bao and Zhang (2020), and Sharma et al. (2020).

The majority of research focused on air quality's spatial transition characteristics. According to Li et al. (2012), China has highland in the southern regions that decrease in the northern regions and become lowlands in the western and eastern regions, which has a notable impact on the climatic conditions and air quality of the region. Using a spatial autocorrelation study, Wang et al. (2019) and Lee et al. (2017) found that values of AQI are spatially dependent in Chinese cities. High amount of AQI can be mainly seen in 


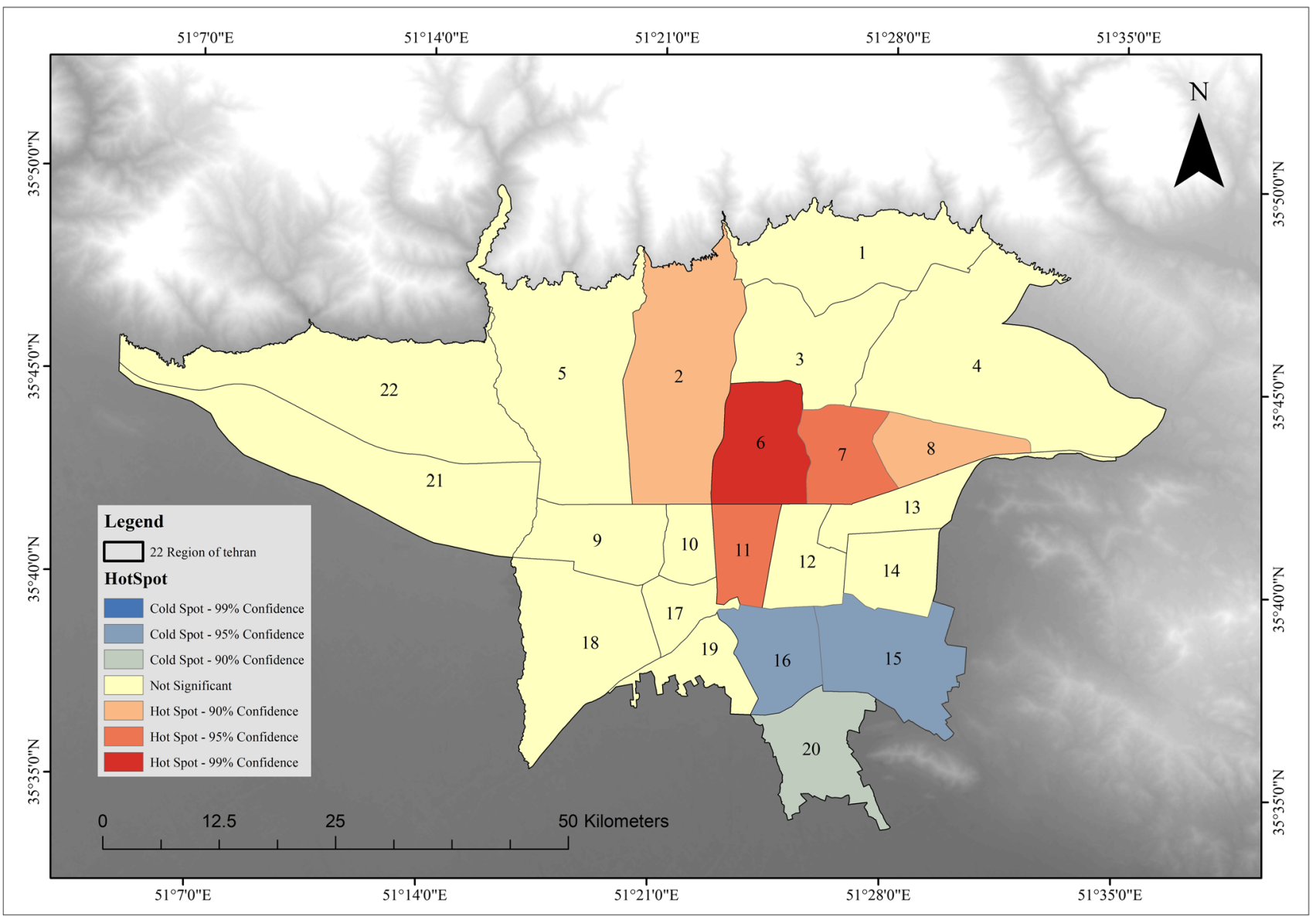

Fig. 10 Patterns and changes in AQI

Table 8 Maximum air quality index and number of days of pollution in the study area

\begin{tabular}{|c|c|c|c|c|c|c|c|c|}
\hline & & $\mathrm{CO}$ & $\mathrm{O}_{3}$ & $\mathrm{NO}_{2}$ & $\mathrm{SO}_{2}$ & PM10 & PM2_5 & AQI \\
\hline \multirow[t]{2}{*}{2017} & Max & 142 & 216 & 135 & 60 & 115 & 175 & 216 \\
\hline & Number of days of pollution - percentage & 0 & $24-40$ & $9-15$ & 0 & 0 & $27-45$ & - \\
\hline \multirow[t]{2}{*}{2018} & Max & 109 & 266 & 103 & 43 & 109 & 172 & 266 \\
\hline & Number of days of pollution - percentage & 0 & $16-26.6$ & 0 & 0 & 0 & $44-73$ & - \\
\hline \multirow[t]{2}{*}{2019} & $\operatorname{Max}$ & 62 & 88 & 105 & 47 & 102 & 148 & 148 \\
\hline & Number of days of pollution - percentage & 0 & $1-1.6$ & $21-35$ & 0 & 0 & $38-63$ & - \\
\hline \multirow[t]{2}{*}{ 2017-2019 } & Max & 89.33 & 136.33 & 104.6 & 45 & 95.6 & 148.66 & 182 \\
\hline & Number of days of pollution - percentage & 0 & $14-23$ & $10-17$ & 0 & 0 & $36-60$ & - \\
\hline \multirow[t]{2}{*}{2020} & $\operatorname{Max}$ & 57 & 88 & 106 & 169 & 90 & 171 & 171 \\
\hline & Number of days of pollution - percentage & 0 & $1-1.16$ & $6-10$ & $1-1.6$ & 0 & $52-86.7$ & - \\
\hline
\end{tabular}

the northern and northwest region, whereas lower amount of AQI can be mainly seen in the southern and Qinghai regions. $\mathrm{Xu}$ et al. (2017) discovered a significant range of spatial differences in AQI using a GIS software and a map related to heat, with the maximum AQI value in the middle-east region of the plain in Northern China.

\section{Conclusion}

COVID-19 is a human hazard that has had different effects at different times and different places. One of the effects of COVID-19 is its effect on traffic, and its secondary effect is on air quality. This paper examines changes in air quality due 


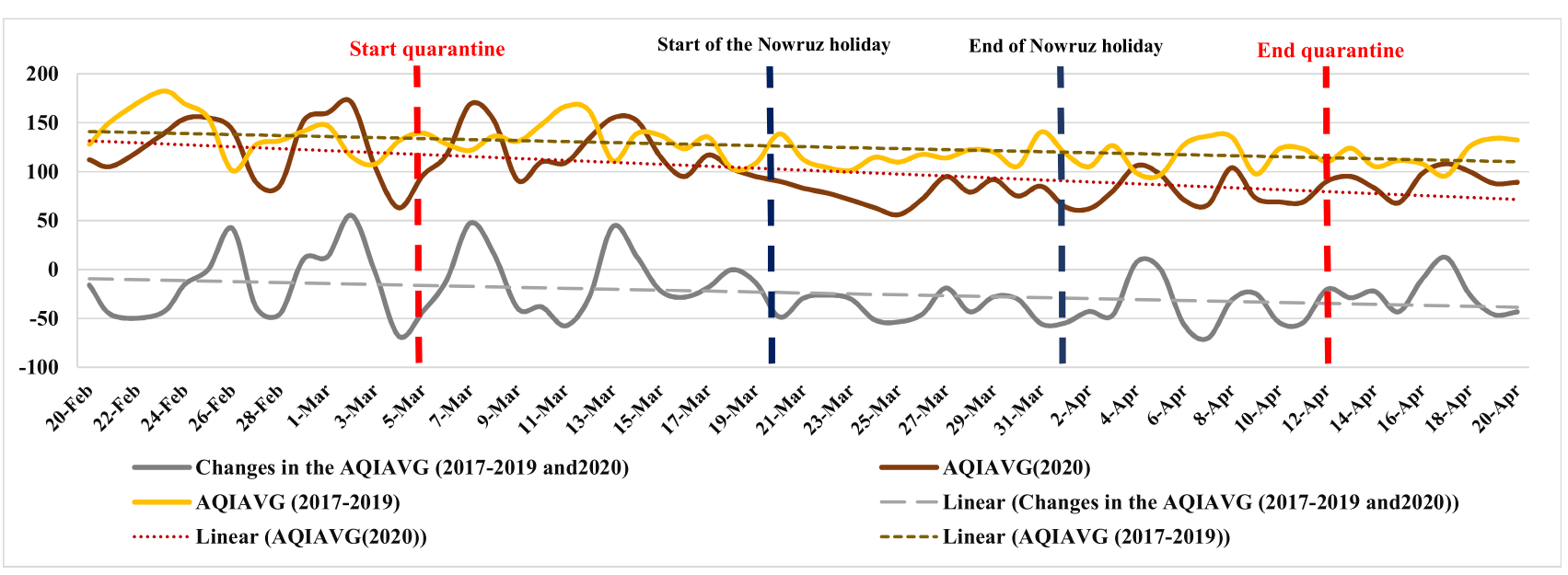

Fig. 11 The trend of changes in the maximum total AQI in Tehran

to the quarantine caused by COVID-19. This study investigated the hourly concentrations of six particulate matters. Findings indicated that changes in pollution rate during the study period can be due to reduced urban traffic, small industrial activities, and dust mites of urban and industrial origins. Although pollution has declined in most regions during the COVID-19 quarantine period, the PM2.5 rate has not decreased significantly, which might be of natural origins such as dust. The results showed that the increasing percentage of the count of days caused by PM2.5 pollution has a sharp increase, which was at the beginning of the curfew on March 2. The AQI slope showed a further decrease compared to previous years. This rate followed a descending pattern until March 27, and the maximum intensity of the fixed trend index increased until April 12. The results of this study indicate that the quarantine has not been able to significantly affect the mean air quality index; this is because of the use of private cars instead of public transport, which is more evident in areas 6 and 7. On the other hand, the maximum air quality index expressed in Fig. 10 has decreased. Spatial autocorrelation analysis has shown a positive correlation between changes in decrease or increase in indicators. Finally, it can be said that although COVID-19 can affect the rate of contamination in a short period of time, due to the prevalence of COVID-19 in crowded places such as public transport fleets, people have been forced to use personal items, and as a result, pollution has increased.

This thesis used interpolation models and spatial autocorrelation to quantify pollutant fluctuations during the Iran lockdown while taking into account the key meteorological factors at play. The credibility of our findings is supported by the robust effects of spatial autocorrelations and contributing factors. This research is intended to contribute to a better understanding of the COVID-19 epidemic's spatiotemporal dynamics and contributing factors. Furthermore, officials at all levels of government will benefit from this research in terms of scientific prevention and management of the disease.

Acknowledgements Appreciations are extended to the General Department of the Environment, especially the Air and Climate Office, Tehran, for providing the time series data.

Author contribution Conceptualization, methodology, data collection and analyses, MK; writing review, editing, supervision, HH, NM, and HA; writing review, editing, JS.

Data availability Raw data were generated from the University of Shahid Beheshti. We confirm that the data, models, or methodology used in the research are proprietary, and derived data supporting the findings of this study are available from the first author on request.

\section{Declarations}

Ethics approval This article does not contain any studies with human participants performed by any of the authors.

Consent to participate This article does not contain any studies with human participants performed by any of the authors.

Competing interests The authors declare no competing interests.

\section{References}

Afify MA, Alqahtani RM, Alzamil MA, Khorshid FA, Almarshedy SM, Alattas SG, Alrawaf TN, Bin-Jumah M, Abdel-Daim MM, Almohideb M (2021) Correlation between polio immunization coverage and overall morbidity and mortality for COVID-19: an epidemiological study. Environ. Sci Pollut Res 1-8 
Ahamed A, Knight R, Alam S, Pauloo R, Melton F (2022) Assessing the utility of remote sensing data to accurately estimate changes in groundwater storage. Sci Total Environ 807:150635

Ahmadi M, Sharifi A, Dorosti S, Ghoushchi SJ, Ghanbari N (2020) Investigation of effective climatology parameters on COVID-19 outbreak in Iran. Sci Total Environ 729:138705

Alsafadi K, Mohammed S, Mokhtar A, Sharaf M, He H (2021) Fineresolution precipitation mapping over Syria using local regression and spatial interpolation. Atmos Res 256:105524

Aquilina NJ, Havel CM, Cheung P, Harrison RM, Ho KF, Benowitz NL et al (2021) Ubiquitous atmospheric contamination by tobacco smoke: nicotine and a new marker for tobacco smoke-derived particulate matter, nicotelline. Environ Int 150:106417

Arora R (2018) Assessment of the mortality burden associated with ambient air pollution in rural and urban areas of India. M.S., University of Southern California

Atta HA (2020) Assessment and geographic visualization of salinity of Tigris and Diyala rivers in Baghdad City. Environ Tech Innovation 17:100538

Azizsafaei M, Sarwar D, Fassam L, Khandan R, Hosseinian-Far A (2021) A Critical Overview of Food Supply Chain Risk Management. In Cybersecurity, Privacy and Freedom Protection in the Connected World: Proceedings of the 13th International Conference on Global Security, Safety and Sustainability, London, January 2021. (Cybersecurity, Privacy and Freedom Protection in the Connected World). Springer, pp 413-429

Bai Y, Yao L, Wei T, Tian F, Jin DY, Chen L, Wang M (2020) Presumed asymptomatic carrier transmission of COVID-19. JAMA 323(14):1406-1407

Bao R, Zhang A (2020) Does lockdown reduce air pollution? Evidence from 44 cities in northern China. Sci of the Total Environ $731: 139052$

Bauwelinck M, Chen J, .... Hoek G (2022) Variability in the association between long-term exposure to ambient air pollution and mortality by exposure assessment method and covariate adjustment: a census-based country-wide cohort study. Sci Total Environ 804: 150091

Beauchamp M, Malherbe L, De Fouquet C, Létinois L, Tognet F (2018) A polynomial approximation of the traffic contributions for kriging-based interpolation of urban air quality model. Environ Model Soft 105:132-152

Becker S, Soukup JM (1999) Exposure to urban air particulates alters the macrophage-mediated inflammatory response to respiratory viral infection. J Toxicol Environ Health Sci 57(7):445-457

Berman JD, Ebisu K (2020) Changes in US air pollution during the COVID-19 pandemic. Sci of the Total Environ 739:139864

Berman JD, Ebisu K (2020) Changes in US air pollution during the COVID-19 pandemic. Sci Total Environ 739:139864

Bonilla-Aldana DK, Holguin-Rivera Y, Cortes-Bonilla I, CardonaTrujillo MC, García-Barco A, Bedoya-Arias HA, ... RodriguezMorales AJ (2020) Coronavirus infections reported by ProMED, February 2000-January 2020. Travel Med Infect Dis. https://doi. org/10.1016/j.tmaid.2020.101575

Bosboom J, Mol M, Reniers AJHM, Stive MJF, De Valk CF (2020) Optimal sediment transport for morphodynamic model validation. Coast Eng 158:103662

Brindha JEG (2021) An hierarchical approach for automatic segmentation of leaf images with similar background using kernel smoothing based Gaussian process regression. Ecol Informatics 63:101323

Briz-Redón Á, Belenguer-Sapiña C, Serrano-Aroca Á (2021) Changes in air pollution during COVID-19 lockdown in Spain: a multi-city study. J Environ Sci 101:16-26

Cai QC, Lu J, Xu QF, Guo Q, Xu DZ, Sun QW, ... Jiang QW (2007) Influence of meteorological factors and air pollution on the outbreak of severe acute respiratory syndrome. Public Health 121(4): 258-265

Cao H, Xie X, Wang Y, Liu H (2022) Predicting geogenic groundwater fluoride contamination throughout China. J Environ Sci 115:140-148

Chen H, Guo J, Wang C, Luo F, Yu X, Zhang W, Li J, Zhao D, Xu D, Gong Q, Liao J (2020a) Clinical characteristics and intrauterine vertical transmission potential of COVID-19 infection in nine pregnant women: a retrospective review of medical records. Lancet 395(10226):809-815

Chen Q-X, Huang C-L, Yuan Y, Tan H-P (2020b) Influence of COVID19 event on air quality and their association in Mainland China. Aerosol Air Qual Res 20:1541-1551

Chen QX, Huang CL, Yuan Y, Tan HP (2020c) Influence of COVID19 event on air quality and their association in Mainland China. Aeros Air Qual Res 20(7):1541-1551

Coccia M (2021) Effects of the spread of COVID-19 on public health of polluted cities: results of the first wave for explaining the dejà $\mathrm{vu}$ in the second wave of COVID-19 pandemic and epidemics of future vital agents. Environ Sci Pollut Res 28(15):19147-19154

CPCB (Central Pollution Control Board) (2014) Central pollution control board continuous ambient air quality. http://www.cpcb.gov.in/ CAAQM/frmUserAvgReportCriteria.aspx. Accessed Mar 2014

Dadhich AP, Goyal R, Dadhich PN (2018) Assessment of spatiotemporal variations in air quality of Jaipur city, Rajasthan, India. Egypt J Remote Sens Space Sci 21(2):173-181

Draper C, Reichle R, De Jeu R, Naeimi V, Parinussa R, Wagner W (2013) Estimating root mean square errors in remotely sensed soil moisture over continental scale domains. Remote Sens Environ 137:288-298

Esmaeilbeigi M, Chatrabgoun O, Hosseinian-Far A, Montasari R, Daneshkhah A (2020) A low cost and highly accurate technique for big data spatial-temporal interpolation. Appl Numer Math 153:492-502

Farzin S, NabizadehChianeh F, ValikhanAnaraki M, Mahmoudian F (2020) Introducing a framework for modeling of drug electrochemical removal from wastewater based on data mining algorithms, scatter interpolation method, and multi criteria decision analysis (DID). J Clean Prod 266:122075

Filonchyk M, Hurynovich V, Yan H, Gusev A, Shpilevskaya N (2020) Impact assessment of COVID-19 on variations of SO2, NO2, CO and AOD over East China. Aerosol Air Qualit Res 20(7):1530-1540

Gagliardi V, BianchiniCiampoli L, Trevisani S, D'amico F, Alani AM, Benedetto A, Tosti F (2021) Testing Sentinel-1 SAR interferometry data for airport runway monitoring: a geostatistical analysis. Sensors 21:5769

Gauderman WJ, Urman R, Avol E, Berhane K, McConnell R, Rappaport E, Chang R, Lurmann F, Gilliland F (2015) Association of improved air quality with lung development in children. N Engl J Med 372:905-913

Getis A, Ord JK (2010) The analysis of spatial association by use of distance statistics. In Perspectives on spatial data analysis (pp 127-145). Springer, Berlin, Heidelberg

He MZ, Kinney PL, Li T, Chen C, Sun Q, Ban J, Wang J, Liu S, Goldsmith J, Kioumourtzoglou MA (2020) Short-and intermediateterm exposure to $\mathrm{NO} 2$ and mortality: a multi-county analysis in China. Environ Pollut 261:114165

Horne BD, Joy EA, Hofmann MG, Gesteland PH, Cannon JB, Lefler JS, Blagev DP, Korgenski EK, Torosyan N, Hansen GI, Kartchner D (2018) Short-term elevation of fine particulate matter air pollution and acute lower respiratory infection. Am J Respir Crit Care Med 198(6):759-766

Hossain SMZ, Sultana N, Mohammed ME, Razzak SA, Hossain MM (2022) Hybrid support vector regression and crow search algorithm for modeling and multiobjective optimization of 
microalgae-based wastewater treatment. J Environ Manage $301: 113783$

IMO (Iran Meteorological Organization) (2019) Meteorological synoptic stations report. http://www.irimo.ir. Accessed Mar 2020

Iran Health Organization (2020) Coronavirus disease 2019 (COVID19) situation report. https://behdasht.gov.ir/. Accessed Apr 2020

Jiang F, Deng L, Zhang L, Cai Y, Cheung CW, Xia Z (2020a) Review of the Clinical Characteristics of Coronavirus Disease 2019 (COVID-19) J Gen Intern Med 35(5):1545-1549

Jiang L, Bai L (2018) Spatio-temporal characteristics of urban air pollutions and their causal relationships: evidence from Beijing and its neighboring cities. Sci Rep 8(1):1-2

Jiang L, He S, Cui Y, Zhou H, Kong H (2020b) Effects of the socioeconomic influencing factors on $\mathrm{SO} 2$ pollution in Chinese cities: a spatial econometric analysis based on satellite observed data. J Environ Manage 268:110667

Jiang LY, Liu Y, Su WZ, Luo L, Cao YM, Liu WH, Di B, Zhang ZB (2021) Spatial autocorrelation of dengue cases and molecular biological characteristics of envelope gene of dengue virus in Guangzhou, 2019. Zhonghua liu Xing Bing xue za zhi= Zhonghua Liuxingbingxue Zazhi 42(5):878-885

Jung S, Kang H, Sung S, Hong T (2019) Health risk assessment for occupants as a decision-making tool to quantify the environmental effects of particulate matter in construction projects. Build Environ 161:106267

Kakol M, Upson D, Sood A (2020) Susceptibility of Southwestern American Indian tribes to coronavirus disease 2019 (COVID-19). J Rural Health. https://doi.org/10.1111/jrh.12451

Kim YG, Park H, Kim SY, Hong KH, Kim MJ, Lee JS, Park SS, Seong MW (2022) Rates of coinfection between SARS-CoV-2 and other respiratory viruses in Korea. Ann Lab Med 42:110-112

Koike K, Kiriyama T, Lu L, Kubo T, Heriawan MN, Yamada R (2021) Incorporation of geological constraints and semivariogram scaling law into geostatistical modeling of metal contents in hydrothermal deposits for improved accuracy. J Geochem Explor 233:106901

Kumari P, Toshniwal D (2020) Impact of lockdown measures during COVID-19 on air quality-A case study of India. Int J of Environ Health Res 1-8

Lee M, Brauer M, Wong P, Tang R, Tsui TH, Choi C, Cheng W, Lai PC, Tian L, Thach TQ, Allen R (2017) Land use regression modelling of air pollution in high density high rise cities: A case study in Hong Kong. Sci Total Environ 592:306-315

Li X, Zhang M, Wang S, Zhao A, Ma Q (2012) Analysis of the characteristics and influencing factors of China's air pollution index. Environ Sci 33(6): 1936-1943

Li R, Cui L, Li J, Zhao A, Fu H, Wu Y et al (2017) Spatial and temporal variation of particulate matter and gaseous pollutants in China during 2014-2016. Atmosph Environ 161:235-246

Lin B, Zhu J (2018) Changes in urban air quality during urbanization in China. J Clean Prod 188:312-321

Liu Q, Li X, Liu T, Zhao X (2020) Spatio-temporal correlation analysis of air quality in China: evidence from provincial capitals data. Sust 12(6):2486

Luo H, Guan Q, Lin J, Wang Q, Yang L, Tan Z, Wang N (2020) Air pollution characteristics and human health risks in key cities of northwest China. J Environ Manage 269:110791

Mahato S, Pal S, Ghosh KG (2020) Effect of lockdown amid COVID19 pandemic on air quality of the megacity Delhi, India. Sci Total Environ 730:139086

Mao J, Wang L, Lu C, Liu J, Li M, Tang G et al (2020) Meteorological mechanism for a large-scale persistent severe ozone pollution event over eastern China in 2017. J Environ Sci 92:187-199

Mihankhah T, Saeedi M, Karbassi A (2020) A comparative study of elemental pollution and health risk assessment in urban dust of different land-uses in Tehran's urban area. Chemosphere 241:124984. https://doi.org/10.1016/j.chemosphere.2019.124984

Molla A, Zuo S, Zhang W, Qiu Y, Ren Y, Han J (2022) Optimal spatial sampling design for monitoring potentially toxic elements pollution on urban green space soil: a spatial simulated annealing and k-means integrated approach. Sci Total Environ 802:149728

Muhammad S, Long X, Salman M (2020) COVID-19 pandemic and environmental pollution: a blessing in disguise? Sci Total Environ. https://doi.org/10.1016/j.scitotenv.2020.138820

Nguyen TT, .... Ngo HH (2022a). A novel intelligence approach based active and ensemble learning for agricultural soil organic carbon prediction using multispectral and SAR data fusion. Sci Total Environ 804: 150187

Nguyen XC, ...Nguyen DD (2022b) Developing a new approach for design support of subsurface constructed wetland using machine learning algorithms. J Environ Manage 301: 113868

Ogen Y (2020) Assessing nitrogen dioxide (NO2) levels as a contributing factor to the coronavirus (COVID-19) fatality rate. Sci Total Environ 726:138605

Ogunsanwo FO, Ozebo VC, Olurin OT, Ayanda JD, Coker JO, Sowole O, Ogunsanwo BT, Olumoyegun JM, Olowofela JA (2021) Geostatistical analysis of uranium concentrations in North-Western part of Ogun State, Nigeria. J Environ Radioact 237:106706

Pan S, Jung J, Li Z, Hou X, Roy A, Choi Y et al (2020) Air quality implications of COVID-19 in California. Sustain 12(17):7067

Pandey A, Brauer M, Cropper ML, Balakrishnan K, Mathur P, Dey S et al (2021) Health and economic impact of air pollution in the states of India: the Global Burden of Disease Study 2019. Lancet Planet Heal 5(1):e25-e38

Plack A, Bierwirth M, Weber AP, Gunkelmann N (2022) Experimental and atomistic study of high speed collisions of gold nanoparticles with a gold substrate: validation of interatomic potentials. J Aerosol Sci 159:105846

Qu M, Guang X, Zhao Y, Huang B (2021) Spatially apportioning the source-oriented ecological risks of soil heavy metals using robust spatial receptor model with land-use data and robust residual kriging. Environ Pollution 285:117261

Rahman MS, Azad MAK, Hasanuzzaman M, Salam R, Islam ARMT, Rahman MM et al (2021) How air quality and COVID-19 transmission change under different lockdown scenarios? A case from Dhaka City, Bangladesh. Sci Total Environ 762:143161

Rodriguez-Morales AJ, Bonilla-Aldana DK, Tiwari R, Sah R, Rabaan AA, Dhama K (2020) COVID-19, an emerging coronavirus infection: current scenario and recent developments-an overview. J Pure Appl Microbiol 14:6150

Seyedmohammadi J, Esmaeelnejad L, Shabanpour M (2016) Spatial variation modelling of groundwater electrical conductivity using geostatistics and GIS. Model Earth Syst Environ 2:1-10

Sharma S, Zhang M, Gao J, Zhang H, Kota SH (2020) Effect of restricted emissions during COVID-19 on air quality in India. Sci Total Environ 728:138878

Shen L, Wang H, Zhu B, Zhao T, Liu A, Lu W, ...Wang Y (2021) Impact of urbanization on air quality in the Yangtze River Delta during the COVID-19 lockdown in China. J Clean Prod 296: 126561.

Sicard P, De Marco A, Agathokleous E, Feng Z, Xu X, Paoletti E et al (2020) Amplified ozone pollution in cities during the COVID-19 lockdown. Sci Total Environ 735:139542

Song Z, Deng Q, Ren Z (2020) Correlation and principal component regression analysis for studying air quality and meteorological elements in Wuhan, China. Environ Prog Sustain 39(1):13278

Sood L, Sood V (2020) Being African American and rural: a double jeopardy from Covid-19. J Rural Health. https://doi.org/10.1111/ jrh.12459 
Sun Y, ...Wu J (2022) Exposure to air pollutant mixture and gestational diabetes mellitus in Southern California: results from electronic health record data of a large pregnancy cohort. Environ Inter 158: 106888

Venter ZS, Aunan K, Chowdhury S, Lelieveld J (2020) COVID-19 lockdowns cause global air pollution declines. Proc Natl Acad Sci 117(32): 18984-18990

Wang Q, Su M (2020) A preliminary assessment of the impact of COVID-19 on environment-a case study of China. Sci Total Environ 728:138915

Wang Y, Zhao Y (2021) Is collaborative governance effective for air pollution prevention? A case study on the Yangtze river delta region of China. J Environ Manage 292:112709

Wang Y, Duan X, Wang L (2019) Spatial-temporal evolution of PM2. 5 concentration and its socioeconomic influence factors in Chinese cities in 2014-2017. Int J Environ Res Public Health 16(6):985

Wang C, Horby PW, Hayden FG, Gao GF (2020) A novel coronavirus outbreak of global health concern. Lancet 395(10223):470-473

Wang Q, Zhang C (2021) Can COVID-19 and environmental research in developing countries support these countries to meet the environmental challenges induced by the pandemic? Environ Sci and Pollut Res 1-21

World Health Organization (2020) Coronavirus disease 2019 (COVID19) situation report - 105. https://www.who.int/emergencies/disea ses/novel-coronavirus-2019/situationreports

Xie J, Teng J, Fan Y, Xie R, Shen A (2019) The short-term effects of air pollutants on hospitalizations for respiratory disease in Hefei, China. Int J Biometeorol 63(3):315-326

Xiong Y, Wang Y, Chen F, Zhu M (2020) Spatial statistics and influencing factors of the COVID-19 epidemic at both prefecture and county levels in Hubei Province, China. Int J Environ Res Public Health 17(11):3903

Xu L, Zhou J, Guo Y, Wu T, Chen T, Zhong Q et al (2017) Spatiotemporal pattern of air quality index and its associated factors in 31 Chinese provincial capital cities. Air Qual Atmos Health 10(5):601-609

Xu K, Cui K, Young LH, Wang YF, Hsieh YK, Wan S et al (2020) Air quality index, indicatory air pollutants and impact of COVID-19 event on the air quality near central China. Aerosol Air Qual Res 20(6):1204-1221
Xu Q, Li X, Wang S, Wang C, Huang F, Gao Q, Wu L, Tao L, Guo J, Wang W, Guo X (2016) Fine particulate air pollution and hospital emergency room visits for respiratory disease in urban areas in Beijing, China, in 2013. PLoS One 11(4):e0153099

Yousefian F, Faridi S, Azimi F, Aghaei M, Shamsipour M, Yaghmaeian $\mathrm{K}$ et al (2020) Temporal variations of ambient air pollutants and meteorological influences on their concentrations in Tehran during 2012-2017. Sci Rep 10(1):1-11

Zhang J, Li H, Lei M, Zhang L (2021) The impact of the COVID-19 outbreak on the air quality in China: evidence from a quasi-natural experiment. J Clean Prod 296:126475

Zhang M, Lv J (2021) Source apportionment of potentially toxic elements in soils of the Yellow River Delta Nature Reserve, China: The application of three receptor models and geostatistical independent simulation. Environ Pollut 289:117834

Zhao CS, Yang Y, Yang ST, Xiang H, Ge YR, Zhang ZS, Zhao Y, Yu Q (2020) Effects of spatial variation in water quality and hydrological factors on environmental flows. Sci Total Environ 728:138695

Zhao R, Yan R, Chen Z, Mao K, Wang P, Gao RX (2019) Deep learning and its applications to machine health monitoring. Mech Syst Signal Process 115:213-237

Zheng S, Cao CX, Singh RP (2014) Comparison of ground based indices (API and AQI) with satellite based aerosol products. Sci Total Environ 488:398-412

Zhu Y, Xie J, Huang F, Cao L (2020) Association between short-term exposure to air pollution and COVID-19 infection: evidence from China. Sci Total Environ 727:138704

Zoran MA, Savastru RS, Savastru DM, Tautan MN (2020) Assessing the relationship between ground levels of ozone (O3) and nitrogen dioxide (NO2) with coronavirus (COVID-19) in Milan, Italy. Sci of The Tot Environ 740: 140005

Publisher's note Springer Nature remains neutral with regard to jurisdictional claims in published maps and institutional affiliations. 